\title{
Esrrya regulates nephron development and ciliogenesis by controlling prostaglandin synthesis and cooperation with Ppargc1a
}

\author{
Hannah M. Wesselman ${ }^{1 *}$, Ana L. Flores-Mireles ${ }^{2}$, and Rebecca A. Wingert ${ }^{1 *}$ \\ ${ }^{1}$ Department of Biological Sciences, Center for Stem Cells and Regenerative Medicine, \\ Center for Zebrafish Research, Boler-Parseghian Center for Rare and Neglected Diseases, \\ Warren Center for Drug Discovery, University of Notre Dame, Notre Dame, 46556, USA \\ ${ }^{2}$ Department of Biological Sciences, Eck Institute for Global Health, University of Notre Dame, \\ Notre Dame, 46556, USA \\ * Corresponding authors
}

Keywords: cilia, kidney, nephron, differentiation, esrrya, ptgs 1, prostaglandin

\begin{abstract}
Abbreviations: days post fertilization (dpf); distal early (DE); distal late (DL); immunofluorescence (IF); estrogen-related receptor gamma a (esrrya); fluorescent in situ hybridization (FISH); intraflagellar transport (IFT); hours post fertilization (hpf); Kupffer's vesicle $(\mathrm{KV})$; morpholino oligonucleotide (MO); multiciliated cell (MCC); peroxisome proliferatoractivated receptor gamma 1 alpha (pgcla); polycystic kidney disease (PKD); prostaglandin $\mathrm{E}_{2}$ $\left(\mathrm{PGE}_{2}\right)$; prostaglandin-endoperoxide synthase 1 (ptgs 1 ); proximal convoluted tubule (PCT); proximal straight tubule (PST); somite stage (ss); whole mount in situ hybridization (WISH); wildtype (WT)
\end{abstract}

\section{Correspondence:}

Hannah M. Wesselman, Department of Biological Sciences, University of Notre Dame, 100 Galvin Life Sciences, Notre Dame, IN 46556, USA; Email: hwesselm@nd.edu, Phone: (574)-6310910, Fax: (574)-631-7413; ORCID: 0000-0003-2832-3701

Rebecca A. Wingert, Ph.D., Department of Biological Sciences, University of Notre Dame, 100 Galvin Life Sciences, Notre Dame, IN 46556, USA; Email: rwingert@nd.edu, Phone: (574)-6310907, Fax: (574)-631-7413 ORCID: 0000-0003-3133-7549 


\begin{abstract}
Cilia are essential for the ontogeny and function of many tissues, including the kidney. In mammals, Esrr $\gamma$ has been previously established as a significant determinant of renal health, with decreased expression linked to age related dysfunction, cyst formation, and kidney disease. Here, we report that the Esrry vertebrate ortholog estrogen related receptor gamma a (esrrya) is essential for proper cell fate choice within kidney functional units (nephrons) as well as ciliogenesis. Deficiency of esrrya resulted in nephrons with alterations in proximodistal segmentation and a decreased multiciliated epithelial cell populace. Surprisingly, esrrya deficiency disrupted renal ciliogenesis and caused a similar abrogation within the developing node and otic vesicle - all defects that occurred independently of changes in cell polarity or basal body organization. These phenotypes were consistent with interruptions in prostaglandin signaling, and we found that ciliogenesis was rescued in esrrya deficient embryos with exogenous $\mathrm{PGE}_{2}$ or through overexpression of the cyclooxygenase enzyme Ptgs1. Through genetic interaction studies, we found that peroxisome proliferator-activated receptor gamma, coactivator 1 alpha (ppargcla), which acts upstream of Ptgs 1-mediated prostaglandin synthesis, has a synergistic relationship with esrrya in the ciliogenic pathway. These data position esrrya as a novel link between ciliogenesis and nephrogenesis through regulation of prostaglandin signaling and cooperation with ppargcla, and highlight esrrya as a potential new target for future ciliopathic treatments.
\end{abstract}




\section{Introduction}

Cilia are specialized surface organelles that are present on nearly every vertebrate cell where they serve critical functions including mechano- and chemo- sensing. In the case of motile cilia, primary cilia or multiciliated cells (MCCs) can facilitate fluid propulsion. During development, cilia are essential for the establishment and maintenance of planar cell polarity and organization of essential signaling molecules. For example, aberrant ciliogenesis results in disease states of several tissues, including the kidney, liver, pancreas, retina, and central nervous system (Pazour et al., 2019). Cilia defects have been linked to kidney disorders like polycystic kidney disease, Bardet-Biedl syndrome, Joubert syndrome, and many others (McConnachie et al., 2020). Etiologies for these conditions are varied, but many have been linked to mutations in a variety of specialized ciliary proteins. Production and maintenance of healthy cilia also require proper control of the ciliogenic transcriptional program. Such regulators include the RFX family of transcription factors, which are essential for both primary and motile cilia formation, and interactions with Foxj1 that can further regulate the development of motile cilia (Thomas et al., 2010). Furthermore, the hepatocyte nuclear factor 1B (HNF1B) regulates several ciliary genes, thereby contributing to kidney development and/or disease progression (Clissold et al., 2015, Gresh et al., 2004, Heisberger et al., 2005, Naylor et al., 2014, Sander et al., 2019, Thomas et al., 2010).

Recent studies have identified additional genetic networks that influence cilia formation. Among these, peroxisome proliferator-activated receptor (PPAR) gamma, coactivator 1 alpha (ppargcla, known as $\mathrm{PGC1} \alpha$ in mammals) regulates the ciliogenic program, in part, through control of prostanoid production (Chambers et al., 2018, Chambers et al., 2020). ppargcla induces the biosynthesis of prostaglandin $\mathrm{E}_{2}\left(\mathrm{PGE}_{2}\right)$ by promoting the expression of prostaglandinendoperoxide synthase 1 (ptgs1, also known as cyclooxygenase 1 (coxl)) in both the adult mammalian kidney and zebrafish embryonic kidney (Chambers et al., 2020, Tran et al., 2016). In turn, $\mathrm{PGE}_{2}$ is required for proper ciliary outgrowth by modulating intraflagellar transport (Jin et al., 2014). Interestingly, ppargc 1 a expression and $\mathrm{PGE}_{2}$ production are required for nephrogenesis, where they are involved in the pattern formation of nephron tubule segments and mitigate the fate choice between MCC and transporter cell lineages within these segments (Chambers et al., 2018, Chambers et al., 2020, Marra et al., 2019a, Poureetezadi et al., 2016). 
Interestingly, ESRR $\gamma$, an orphan nuclear receptor, has been found to interact with both HNF1B and PGC1 $\alpha$ in multiple contexts. ESRR $\gamma$ and HNF1B cooperate in the regulation of mitochondrial function and proximal kidney cell development (Sander et al., 2019, Zhao et al., 2018). Similarly, ESRR $\gamma$ and PGC1 $\alpha$ bind common hormone response elements in kidney cells, and work synergistically in mitochondrial biogenesis (Liu et al., 2005, Fan et al., 2018, Wang et al., 2008). Phenotypes observed in Esrry knockout models further support its role in the regulation of energy production, as tissues with high energy demand, including the heart and kidney, are dysregulated. Specifically, Esrry knockout mice die soon after birth due to cardiac defects, and the renal tissue of these mice exhibits decreased ureteric branching (Alaynick et al. 2007, Berry et al., 2011). Furthermore, the kidney specific Esrry murine knockout results in kidney cysts and renal dysfunction (Zhao et al., 2018). Collectively, these phenotypes suggest that Esrry may play multiple roles in kidney and cilia development, yet neither analysis of nephron composition nor cilia formation has been reported to date.

Here, we report that esrrya is necessary for proper nephron segmentation and ciliogenesis. In the zebrafish embryonic kidney, or pronephros, we found that deficiency of esrrya resulted in segment patterning defects that included a decreased number of MCCs. Cilia projecting from MCCs and primary epithelial cells were also significantly shortened in both renal and non-renal populations within esrrya deficient animals. These characteristics were strikingly reminiscent of insufficient prostaglandin signaling during development, and indeed we found that esrrya ciliopathic phenotypes were rescued by supplementation of $\mathrm{PGE}_{2}$ or transcripts encoding the biosynthesis enzyme Ptgs1. Additionally, we discovered a synergistic genetic interaction between esrrya and ppargcla that is essential for renal cila formation. These findings provide fundamental new insights about the regulatory networks that direct ciliogenesis and renal development.

\section{Results}

\section{esrrya is expressed in renal progenitors}

Prior research has demonstrated that Esrry is expressed in the mouse and human kidney, with particularly high expression profiles in the loop of Henle (RID: N-GK5G, 2-5CE6, 2-5CEA, 165WSW) (Harding et al., 2011, Lindstrom et al., 2020, McMahon et al., 2008). Due to evolutionary whole genome duplication events, zebrafish have two homologs for Esrry-esrrya, and esrr $\gamma b$ 
(Thome et al., 2014). Of these, only esrrya is specifically expressed in a pattern consistent with its localization to renal progenitors and is later the distal nephron region, while esrryb is not spatially restricted through early developmental stages (Bertrand et al., 2007, Thisse and Thisse, 2008).

To further assess the expression of esrrya during pronephros ontogeny, we performed whole mount in situ hybridization (WISH) in wild-type (WT) embryos. Since renal progenitors are patterned into distinct segments by the 28 ss (Figure 1A), we assessed esrr $\gamma a$ expression between the 5 and 28 somite stage (ss). Transcripts were detected in the bilateral stripes of renal progenitors at the 8 ss, and continued to be expressed in nephron distal tubule segments at the 28 ss (Figure 1B, Supplement 1D). Fluorescent in situ hybridization at the 20 ss revealed that esrrya transcripts colocalize with the essential kidney transcription factor pax $2 a$, as well as nephron marker $c d h 17$ at the 28 ss (Figure 1B). Given this expression pattern throughout nephron development, we hypothesized that esrrya may have roles in segment patterning and/or cellular differentiation.

\section{esrrya is required for nephron segmentation}

In the developing mouse kidney, Esrr $\gamma$ knockout disrupts branching morphogenesis, renal papilla formation, and causes perinatal lethality; additionally, kidney specific Esrry deficiency results in renal cyst formation (Berry et al., 2011, Zhao et al., 2018). To interrogate the function of esrrya during zebrafish pronephros development, we performed loss of function studies using two previously published morpholinos (MOs) (Tohme et al., 2014). Of these, one morpholino was designed to block protein translation (esrrya ATG MO), and the other was designed to interfere with splicing by blocking the exon 1 splice donor site (esrrya SB MO) (Tohme et al., 2014) (Supplement 1A). The esrrya SB MO caused improper splicing between exon 1 and 2 whereby a portion of exon 1 was excised in the process and produced a transcript that encoded a premature stop codon (Supplement 1B-C). Compared to WT embryos, esrrya morphants displayed hydrocephaly, pericardial edema, and otolith malformations at 96 hours post fertilization (hpf) (Figure 1C, Supplement 3A). This combination of morphological phenotypes suggested that nephron segment development and/or ciliary function were compromised. Therefore, we next assessed the effect of esrrya deficiency on each of the nephron segments and distinct ciliated cell populations within the kidney. 
We found that upon knockdown of esrrya, the proximal straight tubule (PST, marked by trpm7) expanded, while the distal late segment (DL, marked by slc12a3) decreased in length at both the 20 ss and 28 ss (Figure 1D, 1E). The proximal convoluted tubule (PCT, marked by slc20ala), the distal early segment (DE, marked by slc12al), and the overall length of the nephron tubule (marked by $c d h 17$ ) remained unchanged (Supplement 2A, 2C-E). The PCT also exhibited successful proximal migration towards the glomerulus and exhibit the correct convoluted morphology by $3 \mathrm{dpf}$ (Supplement 2G). The observed composition changes were notable as early as the 20 ss and were not a result of changes in cell proliferation, cell death, or total cell number (Figure 1F, 1G, Supplement 2H-O). This supports the notion that esrrya operates early specifically throughout nephron formation, as distinct segments are altered.

To further explore the mechanics of these segment changes, we studied another cell type present within the nephron, MCCs. Preceding work from our lab has found that increased monociliated transporter cell identity can be associated with a coordinated decrease in MCC identity (Chambers et al., 2020, Marra et al., 2019a, Marra et al., 2019b). Indeed, we found that esrrya deficiency resulted in a decrease in MCC cell number (marked by odf3b), and co-injection of esrrya RNA was sufficient to rescue the splice blocking morpholino (Figure 1H-I). Fluorescent in situ hybridization (FISH) analysis of the PST domain (marked by the boundaries of trpm7) also revealed a shift towards a transporter cell identity (Figure 1J). While the overall average cell number (calculated by number of DAPI) in this domain did not change, there was an increase in the number of trpm 7 positive cells accompanied by a coordinated decrease of $o d f 3 b$ positive cells (Figure 1K). MCC precursors were also affected in esrrya deficient animals, resulting in a significant decrease in the number of jag2b expressing cells (Supplement 2B, F). Next, we interrogated esrrya loss of function using a genome editing approach. We designed an independent genetic model of esrrya deficiency using CRISPR-Cas9 mutagenesis. Wild-type zebrafish embryos injected with a cocktail of two guide RNAs that targeted exon 1 of esrrya also exhibited a decrease in MCCs (Supplement 1G). As the penetrance of the esrrya crispant phenotypes in F0 mosaic embryos was less consistent than our morpholino models, we continued to use the esrrya morphant models for subsequent analysis. These findings suggest that esrrya contributes to cell fate decisions between the MCC and monociliated transporter cell identity. 


\section{esrrya is required for ciliogenesis in the kidney and other tissues}

Ciliogenesis is a complex process, requiring proper basal body production around the centrioles, amplification of the basal bodies (in the case of MCCs), proper basal body docking at the apical surface, and finally cilia outgrowth, mediated by anterograde and retrograde intraflagellar transport (Spassky \& Meunier, 2017). Previous studies have found that decreased MCC number can be associated with aberrations in ciliogenesis (e.g. decreased cilia outgrowth) (Chambers et al., 2020).

Considering the observed decrease in MCC number in esrrya deficient animals, we investigated whether cilia formation was likewise affected. The intermediate pronephros are comprised of MCCs interspersed amongst monociliated transporter cells (Figure 2A). We first analyzed cryosections of the intermediate nephron of esrrya deficient animals to determine if cell polarity or ciliogenesis was disrupted. We found that morphants successfully established apical basal polarity at $28 \mathrm{hpf}$, as both apical (aPKC) and basolateral ( $\mathrm{N}+\mathrm{K}+$ ATPase) proteins were correctly and separately localized (Figure 2B). Cryosections of $24 \mathrm{hpf}$ morphants analyzed for cilia structures (cilia ( $\alpha$-tubulin), basal bodies ( $\gamma$-tubulin)) revealed that while cilia appear to be decreased, basal bodies were successfully docked, as they localized to the putative apical surface (Figure 2B). Interestingly, some basal bodies observed in esrr $\gamma$ a deficient animals did not appear to be associated with a cilium projection (Figure 2B). These data suggest that esrrya could be contributing to proper cilia formation, though this is likely to occur independently of polarity or basal body docking.

To further explore the role of esrrya in cilia outgrowth, we used immunofluorescence to mark cilia ( $\alpha$-tubulin), basal bodies ( $\gamma$-tubulin), and DAPI in whole mounts of esrrya deficient animals and WT siblings. This was followed by confocal imaging of both the proximal and distal pronephros, to capture cilia protruding from MCCs as well as transporter cells, respectively. Cilia were disrupted in both the proximal and distal pronephros (Figure 2C, Supplement 3D), where cilia length was significantly shorter in esrrya deficient animals compared to WT (Figure 2D, G, Supplement 3E-N). In addition, morphants did not show any significant changes in the number of basal bodies or cell number (Supplement 4A-D). However, esrrya deficient animals had fewer ciliated basal bodies (Figure 2E, H), as well as decreased fluorescent intensity of cilia ( $\alpha$-tubulin) (Figure 2F, I) which is consistent with the aberrant cilia phenotypes we observed in cryosectioned animals. To test the specificity of our splice interfering morpholino, we co-injected animals with 
esrrya cRNA. Supplementation of mature esrrya transcript alongside the morpholino was sufficient to rescue cilia length, ciliated basal bodies, and the fluorescent intensity of $\alpha$-tubulin (Figure 2C-I). From these data, we concluded that esrrya deficiency interferes with cilia formation in both MCCs and renal epithelial cells with a single primary cilium.

In addition to the kidney, cilia are critical to several other tissues across vertebrates. In the zebrafish this includes, but is not limited to, the Kupffer's vesicle (analogous to the mammalian node) and the otic vesicle (ear structure). To determine if esrrya operates solely in the pronephros, we next investigated the effect of esrrya deficiency on these other tissues. We used IF to mark the KV using aPKC (apical surface) and $\alpha$-tubulin (cilia) in both esrrya morphants and WT siblings at the 10 ss (Figure 2J). Like the pronephros, cilia length was significantly reduced in the KV of esrrya deficient animals (Figure 2K). We also used IF to identify cilia and basal bodies in the ear at 4 dpf. Similarly, morphant animals exhibited decreased fluorescence of $\alpha$-tubulin in the region of both macula and cristae structures, the latter of which was nearly absent altogether (Figure 2L). These data are consistent with the phenotypes observed in the pronephros, and suggest that esrrya affects multiple tissues throughout development (e.g. $10 \mathrm{ss}, 24 \mathrm{hpf}, 28 \mathrm{hpf}$, and $4 \mathrm{dpf}$ ).

\section{esrrya promote ciliogenesis and $\mathrm{MCC}$ cell fate by regulating prostanoid biosynthesis}

Previous studies from our lab and others have shown that prostaglandin signaling is required for ciliogenesis and MCC cell fate choice (Chambers et al., 2020, Jin et al., 2014, Marra et al., 2019a, Spassky \& Meunier, 2017). Considering esrrya deficient animals exhibit similar phenotypes as those with defective prostaglandin synthesis (e.g. decreased MCCs and aberrant cilia), we hypothesized that perhaps esrrya operated in a similar manner. Prostaglandin $\mathrm{E}_{2}\left(\mathrm{PGE}_{2}\right)$ was of interest, considering an analog with an improved half-life, 16,16-dimethyl-PGE $2\left(\mathrm{dmPGE}_{2}\right)$, has been able to rescue other animals with aberrant cilia and decreased MCCs (Chambers et al., 2020, Jin et al., 2014, Marra et al., 2019a, Poureetezadi et al., 2016). Using a commercially available ELISA assay, we measured endogenous $\mathrm{PGE}_{2}$ levels in WT and esrrya deficient embryos at the 28 hpf stage. Compared to WT, esrrya knockdown resulted in a significant decrease of PGE $_{2}$ (Figure 3A). This led us to hypothesize that the diminished $\mathrm{PGE}_{2}$ level was the basis for the ciliary and cell fate alterations in esrrya deficient embryos. 
To test this hypothesis, we examined the functional consequence of restoring prostanoid levels in in esrrya deficient embryos. We treated WT and esrrya deficient embryos with $\mathrm{dmPGE}_{2}$ and used WISH of $o d f 3 b$ to assess MCC cell fate (Figure 3B). esrrya deficient embryos treated with 100 $\mu \mathrm{M}$ dmPGE 2 from shield stage until fixation at $24 \mathrm{hpf}$ had an increase in MCC number compared to their DMSO treated siblings, restoring the number similar to that of WT animals (Figure 3C). As observed by previous studies, we found that $\mathrm{dmPGE}_{2}$ was not sufficient to increase MCC number in WT animals (data not shown) (Chambers et al., 2020, Marra et al., 2019a).

Next, we investigated if dmPGE2 was able to restore proper cilia formation. We treated both WT and esrrya morphant animals with $100 \mu \mathrm{M}$ dmPGE2 or vehicle control from shield stage until fixation at $28 \mathrm{hpf}$ and assessed cilia structures using whole mount IF (Figure 3F). In both the proximal and distal tubule, $\mathrm{dmPGE}_{2}$ rescued cilia length (Figure 3G, J), ciliated basal bodies (Figure 3H, K), and corresponding cilia fluorescent intensity (Figure 3I, L) to WT levels. Together, these data suggest that esrrya interacts with the PGE2 pathway to facilitate ciliogenesis and MCC cell fate.

Prostaglandins are formed by the metabolism of arachidonic acid by cyclooxygenase enzymes to form $\mathrm{PGH}_{2}$, which can then be further metabolized by prostaglandin synthase enzymes to form prostanoids. Zebrafish embryos contain four prostaglandin signaling molecules (PGE 2 , PGF2 $\alpha$, $\mathrm{PGI}_{2}$, and TXA2) (Cha et al., 2005). Previous research has shown that cyclooxygenase enzymes (Cox 1 or Cox 2 , encoded by $\operatorname{tgs} 1$, ptgs $2 a / b$ in zebrafish, respectively) are critical for proper ciliogenesis and MCC cell fate (Chambers et al., 2020, Marra et al., 2019a). With this in mind, we hypothesized that esrrya may be contributing to cilia formation through ptgs 1 . We first examined the $2 \mathrm{~kb}$ promoter region of ptgsl for potential binding sites for esrrya. We found one ERR consensus binding motif (AAGGTCA) approximately $1.8 \mathrm{~kb}$ upstream of the $\operatorname{ptgs} 1$ open reading frame (Figure 3D). It is also worth noting that unlike estrogen receptors, ERRs can bind DNA and affect transcription as monomers; thus, one consensus sequence can be sufficient to affect expression (Huppunen et al., 2004). To confirm that esrrya deficiency does affect ptgs 1 transcription, we conducted WISH analysis and qRT-PCR of ptgsl in esrrya deficient animals at 24hpf. The length of the ptgs 1 domain in the pronephros was significantly decreased (Supplement 5A-B), as well as expression in whole animal lysates, as determined by qRT-PCR (Figure 3E). The observed decreased expression of ptgsl further supports our hypothesis esrrya may be 
contributing to cilia formation through regulation of cyclooxygenase enzyme 1 . Next, we sought to determine if ptgsl overexpression alone was sufficient to rescue esrrya deficiency. We first examined the effect of co-injection of ptgs1 RNA with esrrya MO on MCC number (Figure 3B). Like dmPGE 2 treatment, ptgs1 RNA restored MCC number to WT levels (Figure 3C). We then observed the effect of ptgs 1 overexpression on cilia in both MCCs and mono-ciliated cells using IF (Figure 3F). In both proximal and distal segments, we found that ptgs $1 \mathrm{cRNA}$ was sufficient to rescue cilia length (Figure 3G, J), ciliated basal bodies (Figure 3H, K), and the corresponding fluorescent intensity of $\alpha$-tubulin (Figure 3I, L). Again, these phenotypes were not due to changes in basal body or cell number (Supplement 4A-D). From these data, we concluded that esrrya promotes $\mathrm{PGE}_{2}$ synthesis via ptgs 1 to promote MCC specification and cilia outgrowth in both $\mathrm{MCC}$ and transporter cell populations.

\section{esrrya cooperates with ppargc1a to control MCC specification and cilia formation}

Recent studies have found that ppargcla is essential for prostaglandin signaling, nephron formation, and ciliogenesis (Chambers et al., 2018, Chambers et al., 2020). Interestingly, deficiency of this factor results in similar phenotypes that we observed in the case of esrrya deficiency, including decreased DL and skewed MCC cell fate choice (Chambers et al., 2018, Chambers et al., 2020). Considering these similarities, we sought to determine if esrrya and ppargcla are expressed in the same cell population. FISH analysis revealed that esrrya and ppargcla colocalize in the same pan-distal region of the nephron (Figure 4A).

Considering these factors are co-expressed, we designed genetic interaction studies to explore the relationship between esrrya and ppargcla. One strategy to test if multiple genes operate synergistically in a pathway is the use of suboptimal morpholinos (Chambers et al., 2020, Choi et al., 2015, DiBella et al., 2009, Kallakuri et al., 2015, Wagle et al., 2011). Therefore, we injected suboptimal morpholino (SOMO) doses of both esrrya and ppargcla, based on previously published doses (Chambers et al., 2018, Chambers et al., 2020). We then conducted WISH to determine changes in MCC number (Figure 4B). We found that esrrya and ppargcla SOMO alone resulted in no change or a slight yet significant decrease in MCC number when compared to WT, respectively (Figure 4C). However, the combination of both esrrya and ppargcla SOMO together resulted in a significant decrease in MCC number (Figure 4C). 
We then interrogated the synergistic effect of esrrya and ppargcla on cilia formation. Similar to MCC number, esrrya and ppargcla SOMO did not appear to have a significant effect on the appearance of cilia, while the combination injection showed aberrant cilia structures (Figure 4D). Further, esrrya and ppargcla SOMO injections independently did not significantly change ciliated basal bodies nor cilia length in MCC and transporter cell populations. However, combination of the esrrya and ppargcla SOMO significantly decreased the percentage of ciliated basal bodies as well as cilia length in both pronephric regions of interest (Figure 4E-F, H-I). The corresponding fluorescent intensity of the combination SOMO was also significantly decreased when compared to all other treatment groups (Figure 4G, 4J). These changes were not due to alterations in basal body or cell number (Supplement 4I-L). Overall, this evidence is indicative of a cooperative effect between esrrya and ppargcla in the context of ciliogenesis and MCC specification.

\section{Discussion}

Estrogen related receptors, and specifically Esrry, have been previously linked to disease states of tissues with high energy demand. Global Esrry knockout mice and cardiac specific overexpression mice exhibit early lethality due to heart failure (Alaynick et al. 2007, Alaynick et al. 2010, Lasheras et al., 2021). Similar dysfunction is seen in the kidney, as Esrry knockout results in deficient ureteric branching, kidney cysts, and decreased mitochondrial function and solute transportation (Berry et al., 2011, Zhao et al., 2018). In humans, mutations in or decreased expression of ESRR $\gamma$ has been linked to incidence of congenital anomalies of the kidney and urinary tract and chronic kidney disease (Berry et al., 2011, Eichner et al., 2011, Hock et al., 2009, Misra et al., 2017, Zhao et al., 2018). Yet, until our current work, the mechanism by which Esrry contributes to the development of the high energy and ciliated tissues remains poorly understood.

Our work suggests that esrrya works with ppargcla upstream of prostaglandin signaling to facilitate nephron cell development and ciliogenesis. Specifically, esrr $\gamma a$ acts as a "switch" to favor MCC fate, as we see decreased MCC number with a coordinated increase of PST transporter cells and decrease of the DL segment in esrrya deficiency. Additionally, esrrya knockdown resulted in decreased ciliated basal bodies and decreased cilia length in both mono and multiciliated cell populations in the nephron and other tissues. The observed decreased MCC number and aberrant cilia could be rescued by co-injection of $\operatorname{ptgs}_{1}$ or treatment with $\mathrm{dmPGE}_{2}$, showing for the first time that esrrya works upstream of prostanoid production. Furthermore, suboptimal morpholino 
injection of esrrya and ppargcla, genetically mimicking compound heterozygous animals, resulted in phenotypes reminiscent of full dosage animals with decreased MCC number and atypical cilia. Together, these data deepen our understanding of the possible mechanisms contributing to ciliopathic and kidney disease conditions.

Prior to this work, prostaglandins have been established as key bioactive molecule in various tissues, and implicated in disease states relating to inflammation, vascular development, cardiac injury, and kidney disease (Lannoy et al., 2020, FitzSimons et al., 2020, Marra et al., 2019a, Sparks and Coffman, 2010, Ugwuagbo et al., 2019,). In some models, blockade of a prostaglandin receptor (EP4) can improve cystic disease states, yet $\mathrm{PGE}_{2}$ has also been implicated as an essential factor of cilia outgrowth and proper nephron patterning, which together point to the importance of proper spatiotemporal control of prostaglandin dosage. (Chambers et al., 2020, Jin et al., 2017, Lannoy et al., 2020, Marra et al., 2019a, Poureetezadi et al., 2016). Here, we have added to that growing body of knowledge, as dmPGE2 and ptgs 1 were able to rescue both cell type (MCC deficiency) and ciliopathic (ciliated basal bodies, and cilia length) phenotypes. The dmPGE2 treatment was unable to rescue the distal late segment length (data not shown). However, a restoration of the DL was not anticipated as exogenous $\mathrm{dmPGE}_{2}$ and prostaglandin inhibition have been shown to result in the same DL domain decrease (Poureetezadi et al., 2016). These somewhat contradictory findings speak to the importance of precise $\mathrm{PGE}_{2}$ dosage, and also suggests that esrrya may control segmentation of the distal segment through a mechanism independent of prostaglandin signaling. Further research is required to interrogate the mechanism by which the distal segment is regulated. Candidate transcription factors like $t b x 2 b$ may be of interest, as it operates downstream of ppargcla in distal cell fate identity (Chambers et al., 2018, Drummond et al., 2017).

esrrya and ppargcla act similarly upstream of nephron and cilia development in zebrafish, and we found a synergistic relationship these factors. Ciliogenesis is not the first context in which these factors have been linked, and some have even suggested that PGC1a acts as a "protein ligand" of ESRR $\gamma$ (Audet-Walsh and Giguere, 2014). Both esrrya and ppargcla have been independently implicated in mitochondrial function and various disorders, including diabetes and kidney disease (Audet-Walsh and Giguere, 2014, Guo et al., 2015, Ishimoto et al., 2017, Knutti and Kralli, 2001, Long et al., 2016, Misra et al., 2017, Poidatz et al., 2012, Sharma et al., 2013, Zhao et al., 2018). Further, Esrry and Ppargcla have been shown to bind the same multiple hormone response element 
in the context of kidney specific and other cell lines (Liu et al., 2005, Wang et al., 2008). While the present studies have shown a strong and consistent interaction between esrrya and ppargcla, cilia structure and specific nephron cell types were not evaluated. While we have begun filling this gap in knowledge through our suboptimal morpholino combination experiments, future studies are needed to elucidate the molecular nature of this relationship. In particular, it is not yet known if Esrrya and Ppargcla directly bind to one another in the promoter or enhancer region of ptgs 1 or regulate ciliogenesis through some other mechanism. Since both Esrry and Ppargcla have been shown to interact with Hnflb in the context of kidney tissue, especially in ciliopathic conditions, it is possible that this factor may act as the link in this synergistic relationship (Casemayou et al., 2017, Verhave et al., 2016, Zhao et al., 2018). Furthermore, neither esrrya or ppargcla deficiency alone is sufficient to eradicate all pronephric MCCs and cilia. This may be due to redundant function of esrryb, as esrr $\gamma a / b$ function redundantly in the development of the otic vesicle (Tohme et al., 2014). Alternatively, maternal deposition of either of these factors could explain the basal level of cilia production or perhaps the presence of other ciliogenic factors is sufficient to compensate for esrrya and ppargcla loss to drive low levels of ciliogenesis. Future studies may be interested in the interaction with esrrya/ppargcla and other known components of the ciliogenesis network (e.g. foxj1, gmnc, and mulitcillin) (Choksi et al., 2014, Spassky and Meunier, 2017). It is possible that complete absence of MCCs and cilia is only possible when animals are deficient in multiple factors within the cilia regulatory program.

The link between ciliopathies and aberrant kidney structure and function has long been established (Wang et al., 2013, Winyard et al., 2011), yet the relationship between nephrogenesis and ciliogenesis remains poorly understood. Our work has identified a novel role for esrrya at the nexus of kidney and cilia formation through prostaglandin signaling and cooperation with ppargcla. This discovery suggests that Esrry is an important component in maintaining kidney health and implicates Esrry as a key regulator of ciliogenesis in other tissues. Other studies have already recognized the potential of ERRs as targets for aging kidney treatment. Specifically, treating with pan-ERR agonists results in remarkable improvements in mitochondrial function and albuminaria (Wang et al., 2020). Our findings support this trend, as Esrry may serve as a future therapeutic target, and considering the worldwide prevalence of kidney failure and ciliopathies, novel targets are of the upmost importance. 


\section{References}

Berry, R., Harewood, L., Pei, L., Fisher, M., Brownstein, D., Ross, A., Alaynick, W. A., Moss, J., Hastie, N. D., Hohenstein, P., Davies, J. A., Evans, R. M., \& FitzPatrick, D. R. (2011). Esrrg functions in early branch generation of the ureteric bud and is essential for normal development of the renal papilla. Human Molecular Genetics, 20(5), 917-926. https://doi.org/10.1093/hmg/ddq530

Bertrand, S., Thisse, B., Tavares, R., Sachs, L., Chaumot, A., Bardet, P.-L., Escrivà, H., Duffraisse, M., Marchand, O., Safi, R., Thisse, C., \& Laudet, V. (2007). Unexpected Novel Relational Links Uncovered by Extensive Developmental Profiling of Nuclear Receptor Expression. PLoS Genetics, 3(11), e188. https://doi.org/10.1371/journal.pgen.0030188

Cha, Y. I., Kim, S.-H., Solnica-Krezel, L., \& DuBois, R. N. (2005). Cyclooxygenase-1 signaling is required for vascular tube formation during development. Developmental Biology, 282(1), 274283. https://doi.org/10.1016/j.ydbio.2005.03.014

Chambers, J. M., Addiego, A., Flores-Mireles, A. L., \& Wingert, R. A. (2020). Ppargc1a Controls Ciliated Cell Development by Regulating Prostaglandin Biosynthesis. Cell Reports, 33(6), 108370. https://doi.org/10.1016/j.celrep.2020.108370

Chambers, J. M., Poureetezadi, S. J., Addiego, A., Lahne, M., \& Wingert, R. A. (2018). Ppargc1a controls nephron segmentation during zebrafish embryonic kidney ontogeny. ELife, 7, e40266. https://doi.org/10.7554/eLife.40266

Choi, S. Y., Baek, J.-I., Zuo, X., Kim, S.-H., Dunaief, J. L., \& Lipschutz, J. H. (2015). Cdc42 and sec10 Are Required for Normal Retinal Development in Zebrafish. Investigative Opthalmology \& Visual Science, 56(5), 3361. https://doi.org/10.1167/iovs.14-15692

Clissold, R. L., Hamilton, A. J., Hattersley, A. T., Ellard, S., \& Bingham, C. (2015). HNF1Bassociated renal and extra-renal disease-an expanding clinical spectrum. Nature Reviews. Nephrology, 11(2), 102-112. https://doi.org/10.1038/nrneph.2014.232

Dhillon, P., Park, J., Hurtado Del Pozo, C., Li, L., Doke, T., Huang, S., Zhao, J., Kang, H. M., Shrestra, R., Balzer, M. S., Chatterjee, S., Prado, P., Han, S. Y., Liu, H., Sheng, X., Dierickx, P., Batmanov, K., Romero, J. P., Prósper, F., ... Susztak, K. (2021). The Nuclear Receptor ESRRA Protects from Kidney Disease by Coupling Metabolism and Differentiation. Cell Metabolism, 33(2), 379-394.e8. https://doi.org/10.1016/j.cmet.2020.11.011

DiBella, L. M., Park, A., \& Sun, Z. (2009). Zebrafish Tsc1 reveals functional interactions between the cilium and the TOR pathway. Human Molecular Genetics, 18(4), 595-606. https://doi.org/10.1093/hmg/ddn384

Drummond, B. E., Li, Y., Marra, A. N., Cheng, C. N., \& Wingert, R. A. (2017). The tbx2a/b transcription factors direct pronephros segmentation and corpuscle of Stannius formation in zebrafish. Developmental Biology, 421(1), 52-66. https://doi.org/10.1016/j.ydbio.2016.10.019 
Eichner, L. J., \& Giguère, V. (2011). Estrogen related receptors (ERRs): A new dawn in transcriptional control of mitochondrial gene networks. Mitochondrion, 11(4), 544-552. https://doi.org/10.1016/j.mito.2011.03.121

Fan, W., He, N., Lin, C. S., Wei, Z., Hah, N., Waizenegger, W., He, M.-X., Liddle, C., Yu, R. T., Atkins, A. R., Downes, M., \& Evans, R. M. (2018). ERR $\gamma$ Promotes Angiogenesis, Mitochondrial Biogenesis, and Oxidative Remodeling in PGC1 $\alpha / \beta$-Deficient Muscle. Cell Reports, 22(10), 2521-2529. https://doi.org/10.1016/j.celrep.2018.02.047

FitzSimons, M., Beauchemin, M., Smith, A.M. Stroh, E.G., Kelpsch, D.J., Lambm M.C., Tootle., T.L., \& Yin., V.P. Cardiac injury modulates critical components of prostaglandin $\mathrm{E}_{2}$ signaling during zebrafish heart regeneration. Sci Rep 10, 3095 (2020). https://doi.org/10.1038/s41598020-59868-6

Fliegauf, M., Benzing, T., \& Omran, H. (2007). When cilia go bad: Cilia defects and ciliopathies. Nature Reviews Molecular Cell Biology, 8(11), 880-893. https://doi.org/10.1038/nrm2278

Gresh, L., Fischer, E., Reimann, A., Tanguy, M., Garbay, S., Shao, X., Hiesberger, T., Fiette, L., Igarashi, P., Yaniv, M., \& Pontoglio, M. (2004). A transcriptional network in polycystic kidney disease. The EMBO Journal, 23(7), 1657-1668. https://doi.org/10.1038/sj.emboj.7600160

Guo, K., Lu, J., Huang, Y., Wu, M., Zhang, L., Yu, H., Zhang, M., Bao, Y., He, J. C., Chen, H., \& Jia, W. (2015). Protective role of PGC-1 $\alpha$ in diabetic nephropathy is associated with the inhibition of ROS through mitochondrial dynamic remodeling. PloS One, 10(4), e0125176. https://doi.org/10.1371/journal.pone.0125176

Harding, S. D., Armit, C., Armstrong, J., Brennan, J., Cheng, Y., Haggarty, B., Houghton, D., Lloyd-MacGilp, S., Pi, X., Roochun, Y., Sharghi, M., Tindal, C., McMahon, A. P., Gottesman, B., Little, M. H., Georgas, K., Aronow, B. J., Potter, S. S., Brunskill, E. W., ... Davidson, D. (2011). The GUDMAP database-An online resource for genitourinary research. Development, 138(13), 2845-2853. https://doi.org/10.1242/dev.063594

Hiesberger, T., Shao, X., Gourley, E., Reimann, A., Pontoglio, M., \& Igarashi, P. (2005). Role of the hepatocyte nuclear factor-1beta (HNF-1beta) C-terminal domain in Pkhd1 (ARPKD) gene transcription and renal cystogenesis. The Journal of Biological Chemistry, 280(11), 10578-10586. https://doi.org/10.1074/jbc.M414121200

Hock, M. B., \& Kralli, A. (2009). Transcriptional control of mitochondrial biogenesis and function. Annual Review of Physiology, 71, 177-203. https://doi.org/10.1146/annurev.physiol.010908.163119

Hoshijima, K., Jurynec, M.J., Klatt Shaw, D., Jacobi, A.M., Behlke, M.A., Grunwald., D.J. (2019). Highly Efficient CRISPR-Cas9-Based Methods for Generating Deletion Mutations and F0 Embryos that Lack Gene Function in Zebrafish. Developmental Cell, 51(5), 645-657. https://doi.org/10.1016/j.devcel.2019.10.004 
Huppunen, J., \& Aarnisalo, P. (2004). Dimerization modulates the activity of the orphan nuclear receptor ERRgamma. Biochemical and Biophysical Research Communications, 314(4), 964 970. https://doi.org/10.1016/j.bbrc.2003.12.194

Ishimoto, Y., Inagi, R., Yoshihara, D., Kugita, M., Nagao, S., Shimizu, A., Takeda, N., Wake, M., Honda, K., Zhou, J., \& Nangaku, M. (2017). Mitochondrial Abnormality Facilitates Cyst Formation in Autosomal Dominant Polycystic Kidney Disease. Molecular and Cellular Biology, 37(24), e00337-17. https://doi.org/10.1128/MCB.00337-17

Jin, D., Ni, T. T., Sun, J., Wan, H., Amack, J. D., Yu, G., Fleming, J., Chiang, C., Li, W., Papierniak, A., Cheepala, S., Conseil, G., Cole, S. P. C., Zhou, B., Drummond, I. A., Schuetz, J. D., Malicki, J., \& Zhong, T. P. (2014). Prostaglandin signalling regulates ciliogenesis by modulating intraflagellar transport. Nature Cell Biology, 16(9), 841-851. https://doi.org/10.1038/ncb3029

Kallakuri, S., Yu, J. A., Li, J., Li, Y., Weinstein, B. M., Nicoli, S., \& Sun, Z. (2015). Endothelial Cilia Are Essential for Developmental Vascular Integrity in Zebrafish. Journal of the American Society of Nephrology, 26(4), 864-875. https://doi.org/10.1681/ASN.2013121314

Knutti, D., \& Kralli, A. (2001). PGC-1, a versatile coactivator. Trends in Endocrinology and Metabolism: TEM, 12(8), 360-365. https://doi.org/10.1016/s1043-2760(01)00457-x

Lannoy, M., Valluru, M. K., Chang, L., Abdela-Ali, F., Peters, D. J. M., Streets, A. J., \& Ong, A. C. M. (2020). The positive effect of selective prostaglandin E2 receptor EP2 and EP4 blockade on cystogenesis in vitro is counteracted by increased kidney inflammation in vivo. Kidney International, 98(2), 404-419. https://doi.org/10.1016/j.kint.2020.02.012

Lasheras, J., Pardo, R., Velilla, M., Poncelas, M., Salvatella, N., Simó, R., Ruiz-Meana, M., Zamora, M., \& Villena, J. A. (2021). Cardiac-Specific Overexpression of ERR $\gamma$ in Mice Induces Severe Heart Dysfunction and Early Lethality. International Journal of Molecular Sciences, 22(15), 8047. https://doi.org/10.3390/ijms22158047

Lindström, N. O., Sealfon, R., Chen, X., Parvez, R., Ransick, A., De Sena Brandine, G., Guo, J., Hill, B., Tran, T., Kim, A. D., Zhou, J., Tadych, A., Watters, A., Wong, A., Lovero, E., Grubbs, B. H., Thornton, M. E., McMahon, J. A., Smith, A. D., ... McMahon, A. P. (2020). Spatial Transcriptional Mapping of the Human Nephrogenic Program. Cell Biology. https://doi.org/10.1101/2020.04.27.060749

Liu, D., Zhang, Z., \& Teng, C. T. (2005). Estrogen-related receptor- $\gamma$ and peroxisome proliferatoractivated receptor- $\gamma$ coactivator- $1 \alpha$ regulate estrogen-related receptor- $\alpha$ gene expression via a conserved multi-hormone response element. Journal of Molecular Endocrinology, 34(2), 473487. https://doi.org/10.1677/jme.1.01586

Marra, A. N., Adeeb, B. D., Chambers, B. E., Drummond, B. E., Ulrich, M., Addiego, A., Springer, M., Poureetezadi, S. J., Chambers, J. M., Ronshaugen, M., \& Wingert, R. A. (2019). Prostaglandin signaling regulates renal multiciliated cell specification and maturation. Proceedings of the National Academy of Sciences, 116(17), 8409-8418. https://doi.org/10.1073/pnas.1813492116 
Marra, A. N., Cheng, C. N., Adeeb, B., Addiego, A., Wesselman, H. M., Chambers, B. E., Chambers, J. M., \& Wingert, R. A. (2019). Iroquois transcription factor irx2a is required for multiciliated and transporter cell fate decisions during zebrafish pronephros development. Scientific Reports, 9(1), 6454. https://doi.org/10.1038/s41598-019-42943-y

McMahon, A. P., Aronow, B. J., Davidson, D. R., Davies, J. A., Gaido, K. W., Grimmond, S., Lessard, J. L., Little, M. H., Potter, S. S., Wilder, E. L., \& Zhang, P. (2008). GUDMAP: The Genitourinary Developmental Molecular Anatomy Project. Journal of the American Society of Nephrology, 19(4), 667-671. https://doi.org/10.1681/ASN.2007101078

Misra, J., Kim, D.-K., \& Choi, H.-S. (2017). ERR $\gamma$ : A Junior Orphan with a Senior Role in Metabolism. Trends in Endocrinology \& Metabolism, 28(4), 261-272. https://doi.org/10.1016/j.tem.2016.12.005

Naylor, R. W., Przepiorski, A., Ren, Q., Yu, J., \& Davidson, A. J. (2013). HNF1 $\beta$ Is Essential for Nephron Segmentation during Nephrogenesis. Journal of the American Society of Nephrology, 24(1), 77-87. https://doi.org/10.1681/ASN.2012070756

Poureetezadi, S. J., Cheng, C. N., Chambers, J. M., Drummond, B. E., \& Wingert, R. A. (2016). Prostaglandin signaling regulates nephron segment patterning of renal progenitors during zebrafish kidney development. ELife, 5, e17551. https://doi.org/10.7554/eLife.17551

Ruiz-Andres, O., Suarez-Alvarez, B., Sánchez-Ramos, C., Monsalve, M., Sanchez-Niño, M. D., Ruiz-Ortega, M., Egido, J., Ortiz, A., \& Sanz, A. B. (2016). The inflammatory cytokine TWEAK decreases PGC-1 $\alpha$ expression and mitochondrial function in acute kidney injury. Kidney International, 89(2), 399-410. https://doi.org/10.1038/ki.2015.332

Sander, V., Salleh, L., Naylor, R. W., Schierding, W., Sontam, D., O’Sullivan, J. M., \& Davidson, A. J. (2019). Transcriptional profiling of the zebrafish proximal tubule. American Journal of Physiology-Renal Physiology, 317(2), F478-F488. https://doi.org/10.1152/ajprenal.00174.2019

Sharma, K., Karl, B., Mathew, A. V., Gangoiti, J. A., Wassel, C. L., Saito, R., Pu, M., Sharma, S., You, Y.-H., Wang, L., Diamond-Stanic, M., Lindenmeyer, M. T., Forsblom, C., Wu, W., Ix, J. H., Ideker, T., Kopp, J. B., Nigam, S. K., Cohen, C. D., ... Naviaux, R. K. (2013). Metabolomics reveals signature of mitochondrial dysfunction in diabetic kidney disease. Journal of the American Society of Nephrology, 24(11), 1901-1912. https://doi.org/10.1681/ASN.2013020126

Sparks, M. A., \& Coffman, T. M. (2010). The EP4 Receptor for Prostaglandin E 2 in Glomerular Disease: A Good Receptor Turned Bad? Journal of the American Society of Nephrology, 21(10), 1597-1599. https://doi.org/10.1681/ASN.2010080870

Spassky, N., \& Meunier, A. (2017). The development and functions of multiciliated epithelia. Nature Reviews Molecular Cell Biology, 18(7), 423-436. https://doi.org/10.1038/nrm.2017.21 Thisse, C., \& Thisse, B. (n.d.). Thisse, C., and Thisse, B. (2008) Expression from: Unexpected Novel Relational Links Uncovered by Extensive Developmental Profiling of Nuclear Receptor Expression. ZFIN Direct Data Submission. https://zfin.org/ZDB-PUB-080220-1(http://zfin.org). 
Thomas, J., Morlé, L., Soulavie, F., Laurençon, A., Sagnol, S., \& Durand, B. (2010). Transcriptional control of genes involved in ciliogenesis: A first step in making cilia. Biology of the Cell, 102(9), 499-513. https://doi.org/10.1042/BC20100035

Tran, M., Tam, D., Bardia, A., Bhasin, M., Rowe, G. C., Kher, A., Zsengeller, Z. K., AkhavanSharif, M. R., Khankin, E. V., Saintgeniez, M., David, S., Burstein, D., Karumanchi, S. A., Stillman, I. E., Arany, Z., \& Parikh, S. M. (2011). PGC-1 $\alpha$ promotes recovery after acute kidney injury during systemic inflammation in mice. Journal of Clinical Investigation, 121(10), 40034014. https://doi.org/10.1172/JCI58662

Tsushida, K., Tanabe, K., Masuda, K., Tanimura, S., Miyake, H., Arata, Y., Sugiyama, H., \& Wada, J. (2018). Estrogen-related receptor $\alpha$ is essential for maintaining mitochondrial integrity in cisplatin-induced acute kidney injury. Biochemical and Biophysical Research Communications, 498(4), 918-924. https://doi.org/10.1016/j.bbrc.2018.03.080

Wagle, M., Mathur, P., \& Guo, S. (2011). Corticotropin-Releasing Factor Critical for Zebrafish Camouflage Behavior Is Regulated by Light and Sensitive to Ethanol. Journal of Neuroscience, 31(1), 214-224. https://doi.org/10.1523/JNEUROSCI.3339-10.2011

Wang, L., Li, Y., Hu, P., \& Teng, C. T. (2008). PGC-1 $\alpha$ induces dynamic protein interactions on the ERR $\alpha$ gene multi-hormone response element nucleosome in kidney cells. Biochemical Journal, 416(3), 407-419. https://doi.org/10.1042/BJ20081085

Wang, X. X., Myakala, K., Libby, A. E., Panov, J., Ranjit, S., Takahashi, S., Jones, B. A., Bhasin, K., Qi, Y., Krausz, K. W., Zerfas, P. M., Velenosi, T. J., Patel, D. P., Daneshpajouhnejad, P., Titievsky, A., Sharov, V., Ostretsov, B., Billon, C., Chatterjee, A., ... Levi, M. (2019). Estrogenrelated receptor agonism reverses mitochondrial dysfunction and inflammation in the aging kidney [Preprint]. Pathology. https://doi.org/10.1101/755801

Zhao, J., Lupino, K., Wilkins, B. J., Qiu, C., Liu, J., Omura, Y., Allred, A. L., McDonald, C., Susztak, K., Barish, G. D., \& Pei, L. (2018). Genomic integration of ERR $\gamma$-HNF1 $\beta$ regulates renal bioenergetics and prevents chronic kidney disease. Proceedings of the National Academy of Sciences, 115(21), E4910-E4919. https://doi.org/10.1073/pnas.1804965115 


\section{Methods}

\begin{tabular}{|c|c|c|}
\hline Reagent or Resource & Source & ID \\
\hline \multicolumn{3}{|l|}{ Antibodies } \\
\hline Anti-tubulin acetylated & Sigma & $\begin{array}{l}\text { T6793; } \\
\text { RRID:AB_477585 }\end{array}$ \\
\hline Anti- $\gamma$-tubulin & Sigma & $\begin{array}{l}\text { T5192; } \\
\text { RRID:AB } 261690\end{array}$ \\
\hline Anti-PKC & Santa Cruz & $\begin{array}{l}\text { SC216; } \\
\text { RRID:AB_2300359 }\end{array}$ \\
\hline Anti-Na ${ }^{+} \mathrm{K}^{+}$ATPase & DSHB & $\begin{array}{l}\text { AB_528092 } \\
\text { RRID:AB } 528092\end{array}$ \\
\hline Anti-Ph3 & Millipore & $06-570$ \\
\hline Anti-Caspase3 & BD Biosciences & 559565 \\
\hline $\begin{array}{l}\text { Goat anti-Mouse IgG }(\mathrm{H}+\mathrm{L}) \text { Highly Cross-Adsorbed } \\
\text { Secondary Antibody, Alexa Fluor } 647\end{array}$ & Invitrogen & $\begin{array}{l}\text { A21236; } \\
\text { RRID:AB_2535805 }\end{array}$ \\
\hline $\begin{array}{l}\text { Goat anti-Rabbit IgG }(\mathrm{H}+\mathrm{L}) \text { Highly Cross-Adsorbed } \\
\text { Secondary Antibody, Alexa Fluor } 647\end{array}$ & Invitrogen & $\begin{array}{l}\text { A21245; } \\
\text { RRID:AB } 141775\end{array}$ \\
\hline $\begin{array}{l}\text { Goat anti-Mouse IgG }(\mathrm{H}+\mathrm{L}) \text { Highly Cross-Adsorbed } \\
\text { Secondary Antibody, Alexa Fluor } 568\end{array}$ & Invitrogen & $\begin{array}{l}\text { A11031; } \\
\text { RRID:AB_144696 }\end{array}$ \\
\hline $\begin{array}{l}\text { Goat anti-Rabbit IgG }(\mathrm{H}+\mathrm{L}) \text { Highly Cross-Adsorbed } \\
\text { Secondary Antibody, Alexa Fluor } 594\end{array}$ & Invitrogen & $\begin{array}{l}\text { A11037; } \\
\text { RRID:AB_2534095 }\end{array}$ \\
\hline $\begin{array}{l}\text { Goat anti-Mouse IgG }(\mathrm{H}+\mathrm{L}) \text { Highly Cross-Adsorbed } \\
\text { Secondary Antibody, Alexa Fluor } 488\end{array}$ & Invitrogen & $\begin{array}{l}\text { A11029; } \\
\text { RRID:AB_138404 }\end{array}$ \\
\hline $\begin{array}{l}\text { Goat anti-Rabbit IgG }(\mathrm{H}+\mathrm{L}) \text { Highly Cross-Adsorbed } \\
\text { Secondary Antibody, Alexa Fluor } 488\end{array}$ & Invitrogen & $\begin{array}{l}\text { A11034; } \\
\text { RRID:AB_2576217 }\end{array}$ \\
\hline \multicolumn{3}{|l|}{ Chemicals } \\
\hline 16,16-Dimethyl-prostaglandin E2 & $\begin{array}{l}\text { Santa Cruz } \\
\text { Biotechnology, } \\
\text { Inc }\end{array}$ & sc-201240 \\
\hline \multicolumn{3}{|l|}{ Commercial Assays } \\
\hline Prostaglandin E2 Express ELISA Kit & $\begin{array}{l}\text { Cayman } \\
\text { Chemical }\end{array}$ & 500141 \\
\hline mMESSAGE mMACHINE SP6 Transcription kit & Ambion & AM1340 \\
\hline PerfeCTa SYBR Green SuperMix with ROX & Quantabio & VWR 101414-160 \\
\hline qScript cDNA SuperMix & Quantabio & VWR 101414-106 \\
\hline TSA Plus Cyanine & $\begin{array}{l}\text { Akoya } \\
\text { Biosciences }\end{array}$ & NEL744001KT \\
\hline TSA Plus Fluorescein & $\begin{array}{l}\text { Akoya } \\
\text { Biosciences }\end{array}$ & NEL741001KT \\
\hline \multicolumn{3}{|l|}{ Oligonucleotides } \\
\hline $\begin{array}{l}\text { esrrya RT-PCR forward } \\
\text { CTGGTGCCAAGCGTTATGAGGACTGTTCCAG }\end{array}$ & This paper & $\mathrm{N} / \mathrm{A}$ \\
\hline $\begin{array}{l}\text { esrrya RT-PCR reverse } \\
\text { GAGGCAGAGCCAGTTGAGGGTTCAAATAGG }\end{array}$ & This paper & N/A \\
\hline
\end{tabular}




\begin{tabular}{|c|c|c|}
\hline $\begin{array}{l}\text { 18S qRT-PCR forward } \\
\text { TCGGCTACCACATCCAAGGAAGGCAGC }\end{array}$ & $\begin{array}{l}\text { Chambers et al., } \\
2020\end{array}$ & $\mathrm{~N} / \mathrm{A}$ \\
\hline $\begin{array}{l}\text { 18S qRT-PCR reverse } \\
\text { TTGCTGGAATTACCGCGGCTGCTGGCA }\end{array}$ & $\begin{array}{l}\text { Chambers et al., } \\
2020\end{array}$ & $\mathrm{~N} / \mathrm{A}$ \\
\hline $\begin{array}{l}\text { ptgs1 qRT-PCR forward } \\
\text { CATGCACAGGTCAAAATGAGTT }\end{array}$ & $\begin{array}{l}\text { Chambers et al., } \\
2020\end{array}$ & N/A \\
\hline $\begin{array}{l}\text { ptgs1 qRT-PCR reverse } \\
\text { TGTGAGGATCGATGTGTTGAAT }\end{array}$ & $\begin{array}{l}\text { Chambers et al., } \\
2020\end{array}$ & $\mathrm{~N} / \mathrm{A}$ \\
\hline $\begin{array}{l}\text { esrrya start site (ATG) morpholino } \\
\text { CAATGTGGCGGTCCTTGTTGGACAT }\end{array}$ & $\begin{array}{l}\text { Tohme et al., } \\
2014 \\
\text { Gene-Tools }\end{array}$ & ZFIN: MO1-esrrga \\
\hline $\begin{array}{l}\text { esrrya splice blocking morpholino } \\
\text { AGGGTAAAAGCCAACCTTGAATGGT }\end{array}$ & $\begin{array}{l}\text { Tohme et al., } \\
2014 \\
\text { Gene-Tools }\end{array}$ & ZFIN: MO2-esrrga \\
\hline $\begin{array}{l}\text { ppargc la morpholino } \\
\text { CCTGATTACACCTGTCCCACGCCAT }\end{array}$ & Gene-Tools & $\begin{array}{l}\text { ZFIN: MO1- } \\
\text { ppargcla }\end{array}$ \\
\hline esrrya crRNA1 TACGCTGTCCGTTAGTGAGG & IDT & $\begin{array}{l}\text { predesigned guide } \\
\text { "AA" }\end{array}$ \\
\hline esrrya crRNA2 CCCACTCTTTATGGCCCAAC & IDT & $\begin{array}{l}\text { predesigned guide } \\
\text { "AC" }\end{array}$ \\
\hline Alt-R® CRISPR-Cas9 tracrRNA & IDT & 1072532 \\
\hline \multicolumn{3}{|l|}{ CRISPR Reagents } \\
\hline Alt-R® S.p. Cas9 Nuclease V3 & IDT & 1081058 \\
\hline Nuclease Free Duplex Buffer & IDT & $11-01-03-01$ \\
\hline \multicolumn{3}{|l|}{ Software } \\
\hline Prism v 9 & GraphPad & $\begin{array}{l}\text { https://www.graphpa } \\
\text { d.com/ } \\
\text { scientific- } \\
\text { software/prism/ }\end{array}$ \\
\hline ImageJ & Fiji & $\begin{array}{l}\text { ImageJ } \\
\text { (https://imagej.nih.g } \\
\text { ov/ij/) }\end{array}$ \\
\hline
\end{tabular}




\section{EXPERIMENTAL MODEL AND SUBJECT DETAILS}

The Center for Zebrafish Research at the University of Notre Dame maintained the zebrafish used in these studies and experiments were performed with approval of the University of Notre Dame Institutional Animal Care and Use Committee (IACUC), under protocol number 19-06-5412.

\section{Animal models}

Tübingen strain WT zebrafish were used for all studies. Zebrafish were raised and staged as described (Kimmel et al., 1995). For all studies, embryos were incubated in E3 medium at $28^{\circ} \mathrm{C}$ until the desired developmental stage, anesthetized with $0.02 \%$ tricaine, and then fixed using $4 \%$ paraformaldehyde/1x PBS (PFA), or Dent's solution (80\% methanol, 20\% DMSO) (Westerfield, 1993, Gerlach et al., 2014). Embryos were analyzed before sex determination, so we cannot report the effect of sex and gender in the context of this study.

\section{METHOD DETAILS}

\section{Whole mount and fluorescent whole mount in situ hybridization (WISH, FISH)}

WISH was performed as previously described (Cheng et al., 2014; Galloway et al., 2008; Lengerke et al., 2011; Marra et al., 2019a, Chambers et al 2020) with antisense RNA probes either digoxigenin-labeled (esrrya, cdh17, odf3b, slc20ala, trpm7, slc12a1, slc12a3, jag2b, ptgs1) or fluorescein-labeled (deltaC, smyhc, pax2a, odf3b, esrrya, cdh17, pgcla, slc12a3) using in vitro transcription using IMAGE clone templates as previously described (Wingert et al., 2007; O'Brien et al., 2011; Gerlach and Wingert, 2014). FISH was performed as described (Brend and Holley 2009; Marra et al., 2017) using TSA Plus Fluorescein or Cyanine Kits (Akoya Biosciences). For all gene expression studies, every analysis was done in triplicate for each genetic model with sample sizes of $n>20$ per replicate.

\section{Sectioning}

Fixed zebrafish samples exposed to $5 \%$ and $30 \%$ sucrose solution and then subjected to a $1: 1$ solution of $30 \%$ sucrose and tissue freezing medium (TFM). Infiltrated samples were embedded 
in $100 \%$ TFM and oriented in Tissue-Tekcryo-molds and frozen at $-80^{\circ} \mathrm{C}$. Sections $(14 \mu \mathrm{m})$ were taken on a Microm HM 550 Cryostat (Thermo).

\section{Immunofluorescence (IF)}

Whole mount IF experiments were completed as previously described (Gerlach and Wingert, 2014; Kroeger et al., 2017; Marra et al.,2017, 2019c, Chambers et al., 2020). For cilia and basal bodies, anti-tubulin acetylated diluted 1:400 (Sigma T6793) and anti $\gamma$-tubulin diluted 1:400 (Sigma T5192) were used, respectively. Cryosectioned samples were completed as previously described (Gerlach and Wingert, 2014). For cilia and basal bodies, anti-tubulin acetylated diluted 1:1000 (Sigma T6793) and anti $\gamma$-tubulin diluted 1:400 (Sigma T5192). For cell polarity, animals were fixed in Dent's solution, and used anti-aPKC diluted 1:500 (Santa Cruz 2300359) to mark apical surface and anti- $\mathrm{Na}^{+} \mathrm{K}^{+}$ATPase diluted 1:35 (DSHB 528092) for a basolateral marker.

\section{Rescue Experiments with dmPGE2}

Chemical treatments were completed as previously described (Marra et al., 2019a; Poureetezadi et al., 2014; Poureetezadi et al., 2016, Chambers et al., 2020). 16,16-dmPGE 2 (Santa Cruz Biotechnology, Inc, SC-201240) was dissolved in 100\% dimethyl sulfoxide (DMSO) to make 1M stocks then diluted to the $100 \mu \mathrm{M}$ treatment dose. Treatments were completed in triplicate with $\mathrm{n}$ $>20$ embryos per replicate. $\mathrm{PGE}_{2}$ metabolite quantification $\mathrm{PGE}_{2}$ metabolite quantifications were completed according to the manufacturer's protocol (Cayman Chemical \#500141). In brief, groups of 25 WT or esrrya MO injected zebrafish were pooled, anesthetized, and flash frozen in 100\% ethanol. Lysates were homogenized and supernatant was isolated after centrifugation at $4^{\circ} \mathrm{C}$ (12,000 RPM for 20 minutes). The kit reagents and manufacturer supplied protocol was followed for assay completion using a plate reader (SpectraMax ABSPlus) at $420 \mathrm{~nm}$.

\section{Quantitative real-time PCR}

Groups of 30 zebrafish (WT, esrrya morphants) were pooled at $24 \mathrm{hpf}$. Trizol (Ambion) was used to extract RNA, qScript cDNA SuperMix (QuantaBio) was used to make cDNA. PerfeCTa SYBR Green SuperMix with ROX (QuantaBio) was used to complete qRT-PCR with 100 ng for ptgs1 and $1 \mathrm{ng}$ for $18 \mathrm{~S}$ controls being optimal cDNA concentrations. The AB StepOnePlus qRT-PCR machine was used with the following program: 2 minute $50^{\circ} \mathrm{C}$ hold, 10 minute $95^{\circ} \mathrm{C}$ hold, then 35 cycles of $15 \mathrm{~s}$ at $95^{\circ} \mathrm{C}$ and 1 minute at $60^{\circ} \mathrm{C}$ for denaturing and primer annealing and product 
extension steps respectively. Each target and source were completed in biological replicates and technical replicates each with the median $\mathrm{Ct}$ value normalized to the control. Data analysis was completed by using delta delta $\mathrm{Ct}$ values comparing WT uninjected siblings to the respective morphant groups with $18 \mathrm{~S}$ as a reference. Primers used include:

To target 18S: forward 5'-TCGGCTACCACATCCAAGGAAGGCAGC-3'

reverse 5'-TTGCTGGAATTACCGCGGCTGCTGGCA-3'.

To target ptgs 1: forward 5'- CATGCACAGGTCAAAATGAGTT- 3'

reverse 5'-TGTGAGGATCGATGTGTTGAAT-3'

\section{cRNA synthesis, and microinjections, rescue studies}

The zebrafish esrrya ORF was cloned in to a pUC57 vector flanked by a 5' KOZAK sequence, single BamH1, SalI and EcoRV restriction sites, and a SP6 promoter region. On the 3' side, the ORF was followed by a series of STOP codons, a SV40 poly A tail, single NDeI, EcoRI, and NotI restriction sites, and a T7 promoter region. esrrya RNA was generated by linearizing with Not1 and SP6 run off with the mMESSAGE mMACHINE SP6 Transcription kit (Ambion). esrrya RNA was injected into WT with or without a co-injection of esrrya splice blocking morpholino at the 1cell stage at a concentration of $500 \mathrm{pg}$. The ptgs 1 ORF was cloned in to a pUC57 vector flanked by a 5' KOZAK sequence, Cla1 restriction site, and a SP6 promoter region. On the 3' side, the ORF was followed by a series of STOP codons, a SV40 poly A tail, a NotI restriction site, and a T7 promoter region. ptgs 1 RNA was generated as with esrrya and injected at $900 \mathrm{pg}$.

\section{CRISPR-Cas9 mutagenesis}

Methods were adapted from Hoshijima et al., (2019). In short, target sequences were selected using the IDT predesign tool, and cross referenced using online program CHOP-CHOP (http://chopchop.cbu.uib.no/index.php). Selected crRNA and tracrRNA tools were obtained (IDT), and dissolved into a $100 \mu \mathrm{M}$ stock with duplex buffer (IDT). To form the crRNA:tracrRNA duplex, equal amounts of crRNA were combined with tracrRNA, and exposed to a rapid heat-slow cool program in a thermocycler. The $50 \mu \mathrm{M}$ duplexed crRNA:tracrRNA was diluted to $25 \mu \mathrm{M}$ with duplex buffer (IDT). Cas9 protein (IDT) was prepared and aliquoted according to the protocol described by Hoshijima et al., (2019). Injection mixes were prepared as follows: $1 \mu 125 \mu \mathrm{M}$ crRNA:tracrRNA (crRNA 1) $+1 \mu 125 \mu \mathrm{M}$ crRNA:tracrRNA (crRNA 2) $+1 \mu 125 \mu \mathrm{M}$ Cas9 protein $+2 \mu 1$ RNase-free water. This mixture was incubated at $37^{\circ} \mathrm{C}$ for 10 minutes, and then stored at 
room temperature. Zebrafish embryos were injected at the one cell stage with $2-3 \mathrm{nl}$ of the $5 \mu \mathrm{M}$ crRNA:tracrRNA:Cas9 mixture.

\section{Genetic models}

Antisense morpholino oligonucleotides (MOs) were obtained from Gene Tools, LLC (Philomath, OR). MOs were solubilized in DNase/RNase free water to generate $4 \mathrm{mM}$ stock solutions which were stored at 20C. Zebrafish embryos were injected at the 1-cell stage with 1-2 $\mathrm{nL}$ of diluted MO. esrrya was targeted with two morpholinos. A start site (ATG) morpholino: 5'CAATGTGGCGGTCCTTGTTGGACAT -3' (667 $\mu \mathrm{M}$ optimal), and a splice blocking morpholino 5'- AGGGTAAAAGCCAACCTTGAATGGT -3'(400 $\mu \mathrm{M}$ optimal, $200 \mu \mathrm{M}$ suboptimal). The latter of which was validated using RT-PCR using the following primers: esrrya RT-PCR forward 5'- CTGGTGCCAAGCGTTATGAGGACTGTTCCAG -3' and esrrya RTPCR reverse 5' - GAGGCAGAGCCAGTTGAGGGTTCAAATAGG-3'. ppargcla was targeted with the following validated MO: 5'-CCTGATTACACCTGTCCCACGCCAT-3' (400 $\mu \mathrm{M}$ optimal, $200 \mu \mathrm{M}$ suboptimal) (Hanai et al., 2007; Bertrand et al., 2007, Chambers et al., 2018, Chambers et al., 2020).

\section{Image acquisition and phenotype quantification}

A Nikon Eclipse Ni with a DS-Fi2 camera was used to image WISH samples and live zebrafish. Live zebrafish were mounted in methylcellulose with trace amounts of tricaine present. IF and FISH images were acquired using a Nikon C2 confocal microscope

\section{QUANTIFICATION AND STATISTICAL ANALYSIS}

Cilia phenotypes were quantified using ImageJ/Fiji (https://imagej.nih.gov) software tools. All measurements were completed on representative samples imaged at $60 \mathrm{X}$ magnification. The multipoint tool was used for counting. The segmented line tool was used for length measurements. Fluorescent intensity plots were generated with the plot profile function. Each experiment was completed in a minimum of triplicate. From these measurements an average and standard deviation (SD) were calculated, and unpaired $t$ tests or one-way ANOVA tests were completed to compare control and experimental measurements using GraphPad Prism 9 software. Statistical details for each experiment are located in the corresponding figure legend. 


\section{ACKNOWLEDGEMENTS}

We would like to thank the generous funders of this work: startup funds from the University of Notre Dame (to R.A.W), Graduate Women in Science National Fellowship (to H.M.W), Warren Center Drug Development Welter Family Fellowship (to H.M.W), and the Notre Dame Center for Stem Cells and Regenerative Medicine Fellowship (to H.M.W). This work would not have been possible without the staffs of the Department of Biological Sciences and the Center for Zebrafish Research at the University of Notre Dame. Imaging seen in this manuscript was carried out in part in the Notre Dame Integrated Imaging Facility (AR1, C2 confocal microscopes), and we especially thank S.C. for her knowledge and expertise. Finally, we express our deep gratitude to the Wingert lab and Wingert lab alumni, J.C and B.C., for their guidance and insight on this project. 


\section{Figures and Figure Legends}

\section{Figure 1}

\section{Esrrya deficient animals exhibit altered morphology and nephron composition}

(A) Schematic of nephrogenesis in a zebrafish from the early 20 ss to the fully patterned 28 ss. Nephron is comprised of the proximal convoluted tubule (PCT), proximal straight tubule (PST), distal early (DE) and distal late (DL) segments. (B) esrrya is expressed in the kidney progenitors at the 20 ss (top) colocalizes with early marker (pax2a). Somites are marked with smyhc stain in red at the 20 ss. At the 28 ss (bottom) esrrya colocalizes with the nephron marker (cdh17). Scale bar $=100 \mu \mathrm{m}$ for lower magnification image, scale bar $=50 \mu \mathrm{m}$ for both higher magnification images(C) WT sibling (top) and esrrya morphant (bottom) zebrafish with pericardial edema (asterisk), hydrocephaly (arrow head), and fused otoliths (dashed box outline, inset). Scale bar $=100 \mu \mathrm{m}$, inset $=50 \mu \mathrm{m}$. (D) $20 \mathrm{ss}$ (left) and 28 ss (right) WT (top) and esrrya MO (bottom) animals stained via WISH for the PST marker $(\operatorname{trpm} 7)$ with either somite marker $(s m y h c)$ or nephron marker $(c d h 17)$. Scale bar $=100 \mu \mathrm{m}$ for lower magnification, scale bar $=50 \mu \mathrm{m}$ for higher magnification. (E) $20 \mathrm{ss}$ (left) and $28 \mathrm{ss}$ (right) WT (top) and esrrya MO (bottom) animals stained via WISH for the DL marker (slc12a3) with either somite marker $(s m y h c)$ or MCC marker $(o d f 3 b)$. Scale bar $=100 \mu \mathrm{m}$ for lower magnification, scale bar $=50 \mu \mathrm{m}$ for higher magnification. (F) PST domain length at $28 \mathrm{ss}$ in micrometers. (G) DL domain length at $28 \mathrm{ss}$ in micrometers. (H) WT (top) and esrrya MO injected (middle and bottom), and esrrya cRNA co-injected (bottom) zebrafish at 24 hpf stained with WISH for MCCs (odf3b). Scale bar = $50 \mu \mathrm{m}$. (I) Absolute number of MCCs per nephron of zebrafish at $24 \mathrm{hpf}$. (J) Fluorescent in situ hybridization for MCCs (odf3b, green), and PST cells (trpm7, red), in WT and esrrya MO injected zebrafish at $24 \mathrm{hpf}$. MCCs are circled in green dotted line. Scale bar $=50 \mu \mathrm{m}$. (K) Absolute cell number of either $o d f 3 b$ or trpm 7 expressing cells in WT and esrrya MO injected animals at 24 hpf. Data presented on graphs are represented as mean $\pm \mathrm{SD} ; * * * \mathrm{p}<0.001$ and $* * * * \mathrm{p}<0.0001$ (t test or ANOVA).

\section{Figure 2}

\section{Esrrya contributes to ciliogenesis independent from cell polarity}

(A) Schematic illustrating the location of MCCs interspersed amongst monociliated transporter cells in the proximal straight tubule (PST) and monociliated cells along in the distal late (DL) segment. (B) Representative cryosections of the nephron (outlined in dotted line) of WT (top) and esrrya MO 
injected zebrafish at $24 \mathrm{hpf}$ (left) and $28 \mathrm{hpf}$ (right). Left panels mark cilia (acetylated a-tubulin), and basal bodies (g-tubulin) and. Arrowhead denotes basal body without colocalized cilia. Right panels mark apical surface $(\mathrm{aPKC})$ and basal bodies $(\mathrm{Na} / \mathrm{K}$ ATPase). Scale bar $=10 \mu \mathrm{m}$. (C) 28 hpf WT (top), esrrya MO injected (middle), and esrrya MO with esrrya cRNA co-injected (bottom) zebrafish stained via whole mount immunohistochemistry for acetylated a-tubulin (cilia, green), g-tubulin (basal bodies, red), and DAPI in the proximal (left) and distal (right) pronephros. Scale bar $=50 \mu \mathrm{m}$. (D) Cilia length in micrometers for the proximal pronephros. (E) Percentage of ciliated basal bodies (ciliated basal bodies/total basal bodies per $100 \mu \mathrm{m}$ ) in the proximal pronephros. (F) Fluorescent intensity plots (cilia, alpha tubulin) for the same relative distance in the proximal pronephros of WT, esrrya MO, and esrrya MO with esrrya cRNA co-injected animals at $28 \mathrm{hpf}$. (G) Cilia length in micrometers for the distal pronephros. (H) Percentage of ciliated basal bodies (ciliated basal bodies/total basal bodies per $100 \mu \mathrm{m}$ ) in the distal pronephros. (I) Fluorescent intensity plots (cilia, alpha tubulin) for the same relative distance in the distal pronephros of WT, esrrya MO, and esrrya MO with esrrya cRNA co-injected animals at $28 \mathrm{hpf}$. (J) Representative image of the Kupffer's vesicle (KV, outlined in dotted line) at the 10 ss stained via immunohistochemistry for acetylated atubulin (cilia, green) and aPKC (apical surface, red) for WT (top) and esrrya MO (bottom). Scale bar $=25 \mu \mathrm{m}$. (K) Cilia length in micrometers for cilia in the KV. (L) Ear structures of WT (top) and esrrya MO (bottom) zebrafish at $4 \mathrm{dpf}$ stained via immunohistochemistry for cilia (green, acetylated alpha tubulin) and basal bodies (red, gamma tubulin). Arrow head denotes macula cilia, dotted line surrounds cristae structures. Dotted area is magnified in right panel. Scale bar left $=50 \mu \mathrm{m}$, scale bar right $=25 \mu \mathrm{m}$. Data presented on graphs are represented as mean $\pm \mathrm{SD} ;{ }^{*} \mathrm{p}<0.05, * * \mathrm{p}<0.01 * * * \mathrm{p}<$ 0.001 and $* * * * \mathrm{p}<0.0001$ ( $\mathrm{t}$ test or ANOVA).

\section{Figure 3}

\section{Esrrya controls ciliogenisis through regulation of prostaglandin signaling}

(A) Relative PGE2 concentration of $28 \mathrm{hpf} \mathrm{WT}$ and esrrya MO injected animals determined via ELISA assay. (B) Representative MCCs stained via WISH (odf3b) of 28 ss WT, esrrya MO, esrrya MO treated with dmPGE2, and esrrya MO co-injected with ptgs 1 cRNA (top to bottom, respectively). Scale bar $=50 \mu \mathrm{m}$. (C) Number of MCCs per nephron of esrrya MO, esrrya MO treated with dmPGE2, and esrrya MO co-injected with ptgs 1 cRNA animals. (D) Schematic illustrating the location of a putative Esrrya binding site with DNA sequence AAGGTCA upstream of the ptgs 1 open reading frame. (E) Relative amount of ptgs 1 mRNA in WT and esrrya MO animals quantified via 
qRT-PCR. (F) 28 hpf WT, esrrya MO, esrrya MO treated with dmPGE2, and esrrya MO co-injected with ptgs 1 cRNA (top to bottom, respectively) zebrafish stained via whole mount immunohistochemistry for acetylated a-tubulin (cilia, green), g-tubulin (basal bodies, red), and DAPI in the proximal (left) and distal (right) pronephros. Scale bar $=50 \mu \mathrm{m}$. (G) Cilia length in micrometers for the proximal pronephros. (H) Percentage of ciliated basal bodies (ciliated basal bodies/total basal bodies per $100 \mu \mathrm{m}$ ) in the proximal pronephros. (I) Fluorescent intensity plots (cilia, alpha tubulin) for the same relative distance in the proximal pronephros at $28 \mathrm{hpf}$. (J) Cilia length in micrometers for the distal pronephros. (K)Percentage of ciliated basal bodies (ciliated basal bodies/total basal bodies per $100 \mu \mathrm{m}$ ) in the distal pronephros. (L) Fluorescent intensity plots (cilia, alpha tubulin) for the same relative distance in the distal pronephros at $28 \mathrm{hpf}$. Data presented on graphs are represented as mean $\pm \mathrm{SD} ; * \mathrm{p}<0.05, * * \mathrm{p}<0.01 * * * \mathrm{p}<0.001$ and $* * * * \mathrm{p}<0.0001$ (t test or ANOVA).

\section{Figure 4}

\section{Esrrya cooperates with pgc1a to facilitate MCC specification and cilia outgrowth}

(A) Expression of pgcla (green) and esrrya (red) marked in fluorescent in situ hybridization in a 24 hpf WT zebrafish Scale bar $=50 \mu \mathrm{m}$. (B) Representative MCCs stained via WISH (odf3b) of 24 ss WT, esrrya sub-optimal MO (SOMO), pgcla SOMO, and esrrya SOMO and pgcla SOMO coinjected (top to bottom, respectively). Scale bar $=50 \mu \mathrm{m}$. (C) Number of MCCs per nephron. (D) 28 hpf WT, esrrya sub-optimal MO (SOMO), pgcla SOMO, and esrrya SOMO and pgcla SOMO coinjected (top to bottom, respectively) zebrafish stained via whole mount immunohistochemistry for acetylated a-tubulin (cilia, green), g-tubulin (basal bodies, red), and DAPI in the proximal (left) and distal (right) pronephros. Scale bar $=50 \mu \mathrm{m}$. (E) Cilia length in micrometers for the proximal pronephros. (F) Percentage of ciliated basal bodies (ciliated basal bodies/total basal bodies per $100 \mu \mathrm{m}$ ) in the proximal pronephros. (G) Model illustrating MCC cell fate and cilia outgrowth by which Esrrya and Pgcla cooperate upstream of ptgs1 and PGE2 production. $(\mathrm{H})$ Cilia length in micrometers for the distal pronephros. (I) Percentage of ciliated basal bodies (ciliated basal bodies/total basal bodies per $100 \mu \mathrm{m}$ ) in the distal pronephros. Data presented on graphs are represented as mean $\pm \mathrm{SD} ;{ }^{*} \mathrm{p}<0.05, * * \mathrm{p}<0.01 * * * \mathrm{p}<0.001$ and $* * * * \mathrm{p}<0.0001$ ( $\mathrm{t}$ test or ANOVA). 


\section{Supplemental Figures and Figure Legends}

\section{Supplement 1}

(A) Schematic illustrating morpholino knockdown tools. Start site (ATG) MO binds to the ATG start site in exon 1. Splice blocking (SB) MO binds to the first exon-intron junction. Dark blue lines indicate WT splicing, while red lines indicate altered splicing resulting from splice blocking MO injection. Arrows show primer locations used for RT-PCR. crRNA1 (light blue) and crRNA2 (green) indicate the relative locations of the guide RNAs used for CRISPR-Cas9 mutagenesis. (B) DNA agarose gel of RT-PCR products of WT (Lane 2) and splice blocking MO (Lane 3) animals. WT band is present at the anticipated $450 \mathrm{bp}$ length while the MO band is smaller (approximately $300 \mathrm{bp}$ ), indicating that part of exon 1 was spliced out. Bands were gel purified and confirmed with sequencing analysis. (C) Schematic illustrating WT protein domains (top), and putative protein resulting from splice blocking MO injection (bottom). (D) esrrya expression (purple) and somite location (deltaC/smyhc, orange) stained via WISH at various stages. Arrow heads indicate esrrya expression domain. Scale bar $=100 \mu \mathrm{m}$. (E) FISH expression of esrrya (green) and $c d h 17$ (red) at the 28 ss. Top is the merged file, middle is cdh17 alone, and bottom is esrrya alone. Scale bar $=50 \mu \mathrm{m}$. (F) FISH expression of esrrya (red) and cdh17 (pax2a) at the 20 ss. Top is the merged file, middle is esrrya alone, and bottom is pax $2 a$ alone. Scale bar $=50 \mu \mathrm{m}$. (G) Representative image of MCCs stained with $o d f 3 b$ via WISH of 24 hpf WT (top) and a confirmed CRISPR-Cas9 esrrya mutant (bottom). Mutant was confirmed via T7 endonuclease assay (data not shown). Scale bar $=50 \mu \mathrm{m}$.

\section{Supplement 2}

(A) WISH of WT (top) and esrrya MO (bottom) zebrafish at $24 \mathrm{hpf}$ stained for PCT (slc20ala, left), or DE (slc12al, right). Scale bar $=50 \mu \mathrm{m}$. (B) WISH of WT (top) and esrrya MO (bottom) zebrafish at $24 \mathrm{hpf}$ stained for MCC precursors $(j a g 2 b)$. Scale bar $=50 \mu \mathrm{m}$. (C) PCT domain length in micrometers. (D) DE domain length in micrometers. (E) Entire nephron tubule length (representative image seen in Figure 1D) in micrometers. (F) Number of MCC precursors per nephron. (G) Representative images of the PCT, marked by WISH of slc20ala, during convolution of WT (top) and esrrya MO (bottom) animals and 3dpf (left) and $4 \mathrm{dpf}$ (right). Scale bar $=50 \mu \mathrm{m}$. (H) 20ss WT (left) and esrrya MO (right) nephrons (outlined with dotted line) stained for the PST (trpm7) via fluorescent in situ hybridization and proliferating (PH3, top) or apoptotic (Caspase3, bottom) cells 
via immunohistochemistry. Arrow heads denote double positive cells. Scale bar $=50 \mu \mathrm{m}$. (I) PST (trpm7) domain length at 20ss in micrometers. (J) Number of PH3 positive cells in the PST at 20 ss (K) Number of Caspase3 positive cells in the PST at 20 ss. (L) 20 ss WT (left) and esrrya MO (right) nephrons (outlined with dotted line) stained for the DL (slc12a3) via fluorescent in situ hybridization and proliferating ( $\mathrm{PH} 3$, top) or apoptotic (Caspase3, bottom) cells via immunohistochemistry. Arrow heads denote double positive cells. Scale bar $=50 \mu \mathrm{m}$. (M) DL (slc12a3) domain length at $20 \mathrm{ss}$ in micrometers. (N) Number of PH3 positive cells in the DL at 20 ss. (O) Number of Caspase3 positive cells in the DL at 20 ss.

\section{Supplement 3}

(A) WT sibling (top) and esrrya morphant (bottom) zebrafish with pericardial edema (asterisk), hydrocephaly (arrow head), and fused otoliths (dashed box outline, inset). Scale bar $=100 \mu \mathrm{m}$, inset $=50 \mu \mathrm{m}$. (B) WT (top) and esrrya MO injected (bottom) zebrafish at 24 hpf stained with WISH for MCCs $(o d f 3 b)$. Scale bar $=50 \mu \mathrm{m}$. (C) Absolute number of MCCs per nephron of zebrafish at $24 \mathrm{hpf}$ (D) $28 \mathrm{hpf}$ WT (top) and esrrya MO (bottom) zebrafish stained via whole mount immunohistochemistry for acetylated a-tubulin (cilia, green), g-tubulin (basal bodies, red), and DAPI in the proximal (left) and distal (right) pronephros. Scale bar $=50 \mu \mathrm{m}$. (E) Number of DAPI cells per $100 \mu \mathrm{m}$ in the proximal pronephros. (F) Number of basal bodies per $100 \mu \mathrm{m}$ in the proximal pronephros. $(\mathrm{G})$ Cilia length in micrometers in the proximal pronephros. $(\mathrm{H})$ Percentage of ciliated basal bodies (ciliated basal bodies/total basal bodies per $100 \mu \mathrm{m}$ ) in the proximal pronephros. (I) Fluorescent intensity plots (cilia, alpha tubulin) for the same relative distance in the proximal pronephros at $28 \mathrm{hpf}$. (J) Number of DAPI cells per $100 \mu \mathrm{m}$ in the distal pronephros. (K) Number of basal bodies per $100 \mu \mathrm{m}$ in the distal pronephros. (L) Cilia length in micrometers for the distal pronephros. (M) Percentage of ciliated basal bodies (ciliated basal bodies/total basal bodies per $100 \mu \mathrm{m}$ ) in the distal pronephros. (N) Fluorescent intensity plots (cilia, alpha tubulin) for the same relative distance in the distal pronephros at $28 \mathrm{hpf}$. Data presented on graphs are represented as mean $\pm \mathrm{SD} ; * \mathrm{p}<0.05, * * \mathrm{p}<0.01 * * * \mathrm{p}<0.001$ and $* * * * \mathrm{p}<0.0001$ (t test or ANOVA).

\section{Supplement 4}

(A) Number of DAPI cells per $100 \mu \mathrm{m}$ in the proximal pronephros. ANOVA statistical test was not significant. (B) Number of basal bodies per $100 \mu \mathrm{m}$ in the proximal pronephros. ANOVA statistical test was not significant. (C) Number of DAPI cells per $100 \mu \mathrm{m}$ in the distal pronephros. ANOVA 
statistical test was not significant. (D) Number of basal bodies per $100 \mu \mathrm{m}$ in the distal pronephros. ANOVA statistical test was not significant. (E) Fluorescent intensity plots (cilia, alpha tubulin) for the same relative distance in the proximal pronephros at $28 \mathrm{hpf}$. Representative images seen in Figure 4D. (F) Fluorescent intensity plots (cilia, alpha tubulin) for the same relative distance in the distal pronephros at $28 \mathrm{hpf}$. Representative images seen in Figure 4D. Data presented on graphs are represented as mean $\pm \mathrm{SD} ;{ }^{*} \mathrm{p}<0.05, * * \mathrm{p}<0.01 * * * \mathrm{p}<0.001$ and $* * * * \mathrm{p}<0.0001$ ( $\mathrm{t}$ test or ANOVA).

\section{Supplemental Figure 5}

(A) Representative expression of ptgsl in WT (top) and esrrya MO (bottom) zebrafish stained via WISH at $24 \mathrm{hpf}$. Scale bar $=100 \mu \mathrm{m}$. (B) Length of the ptgs 1 domain in the pronephros at $24 \mathrm{hpf}$. Data presented on graphs are represented as mean $\pm \mathrm{SD} * * * * \mathrm{p}<0.0001$ ( $\mathrm{t}$ test or ANOVA). 
bioRxiv preprint doi: https://doi.org/10.1101/2021.11.17.468871; this version posted November 19, 2021. The copyright holder for this preprint (which was not certified by peer review) is the author/funder, who has granted bioRxiv a license to display the preprint in perpetuity. It is made

Figure 1

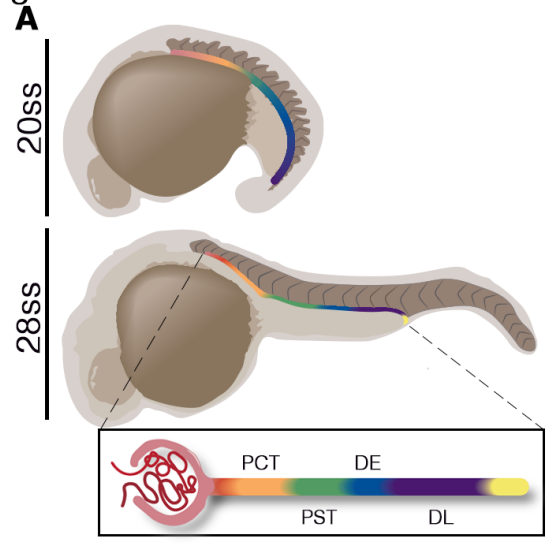
available under aCC-BY-NC-ND 4.0 International license.
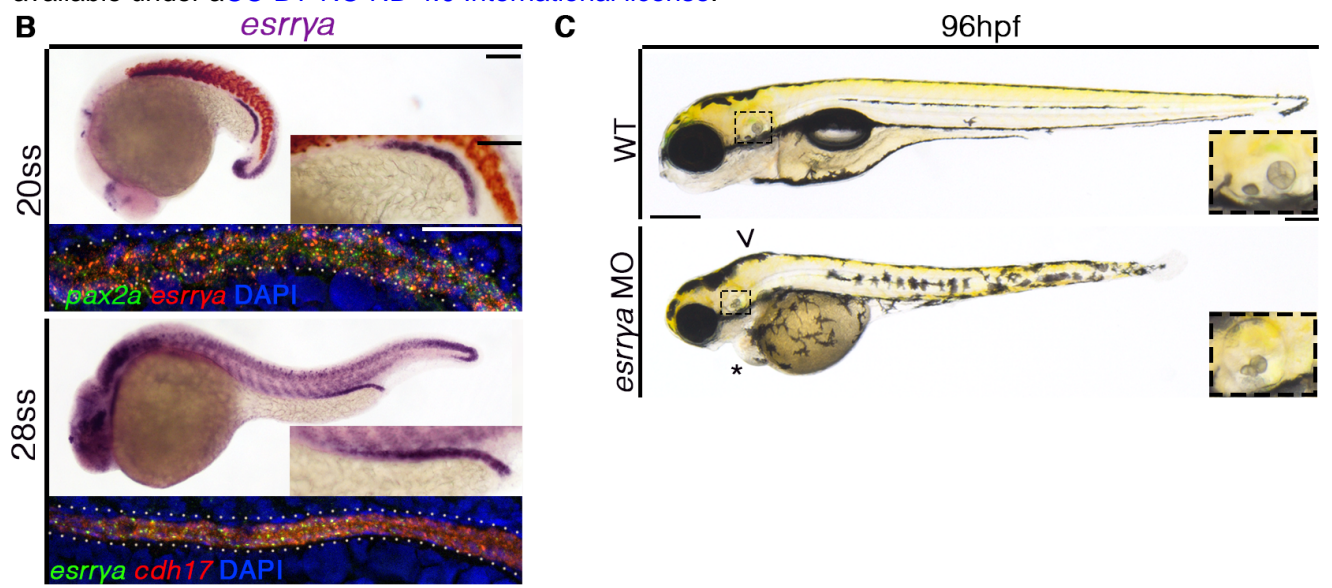

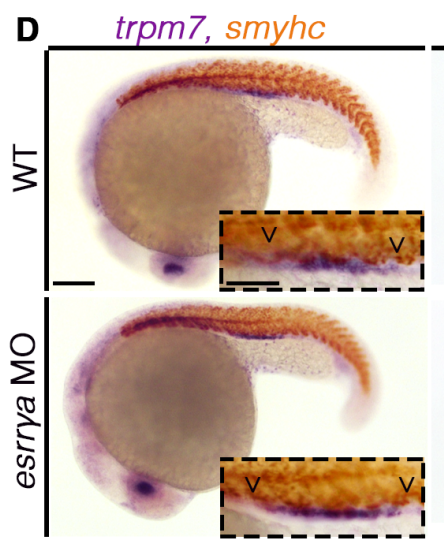

$\mathbf{F}$

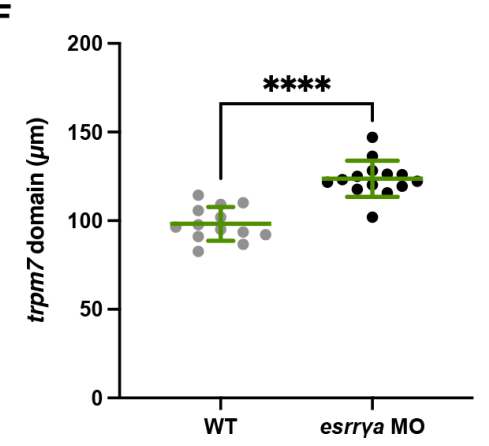

trpm7, colh17

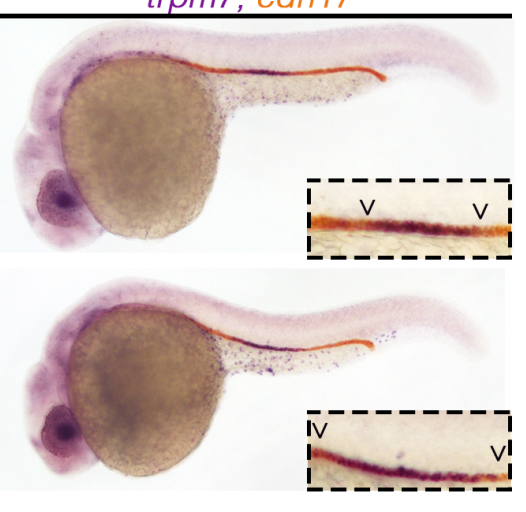

G

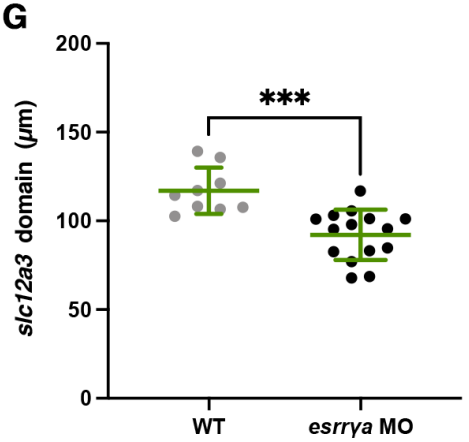

E slc12a3, smvh

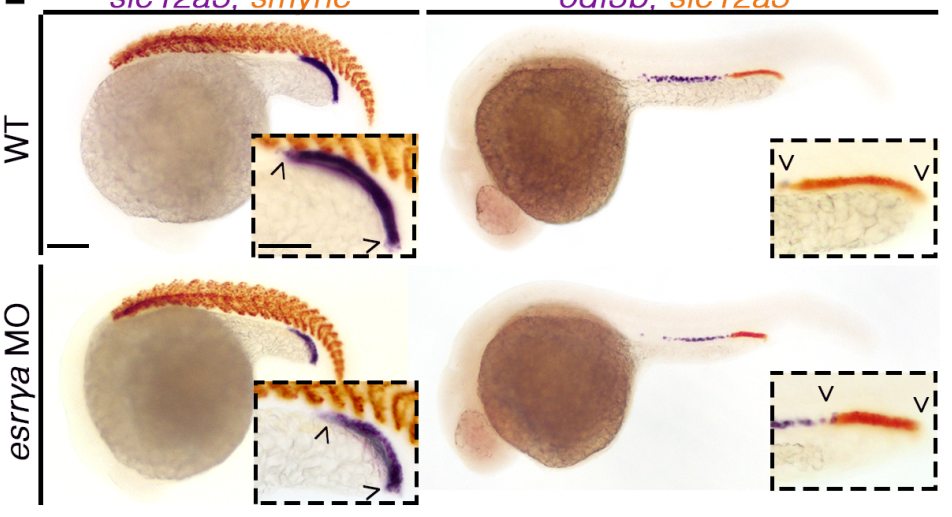

H
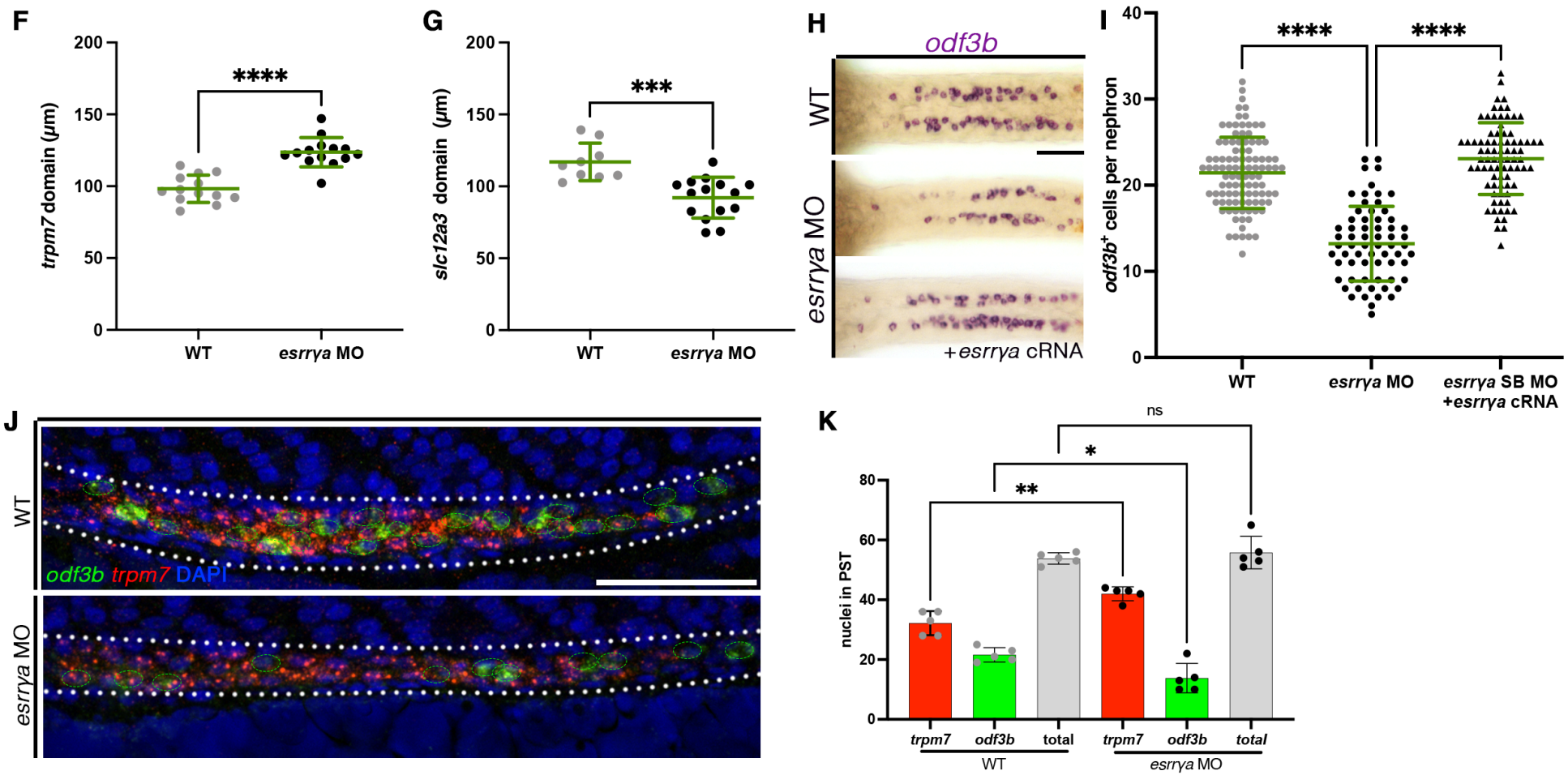
bioRxiv preprint doi: https://doi.org/10.1101/2021.11.17.468871; this version posted November 19,2021 . The copyright holder for this preprint

(which was not certified by peer review) is the author/funder, who has granted bioRxiv a license to display the preprint in perpetuity. It is made

Figure 2

A

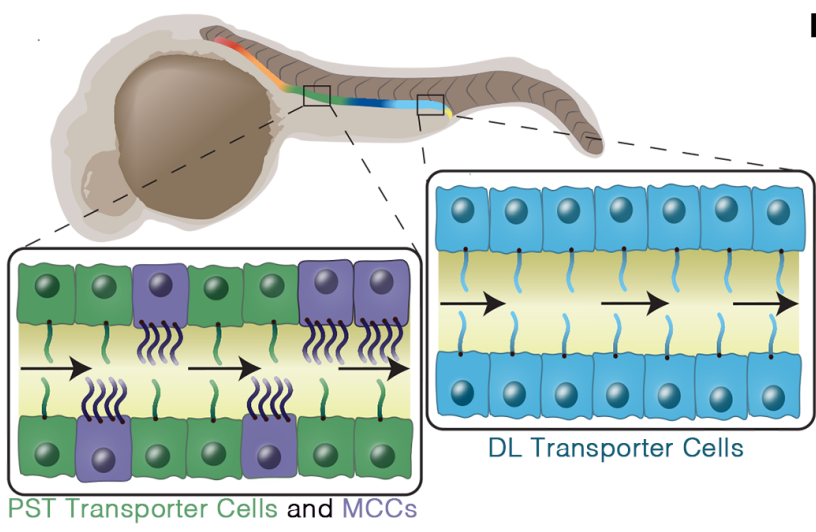

C
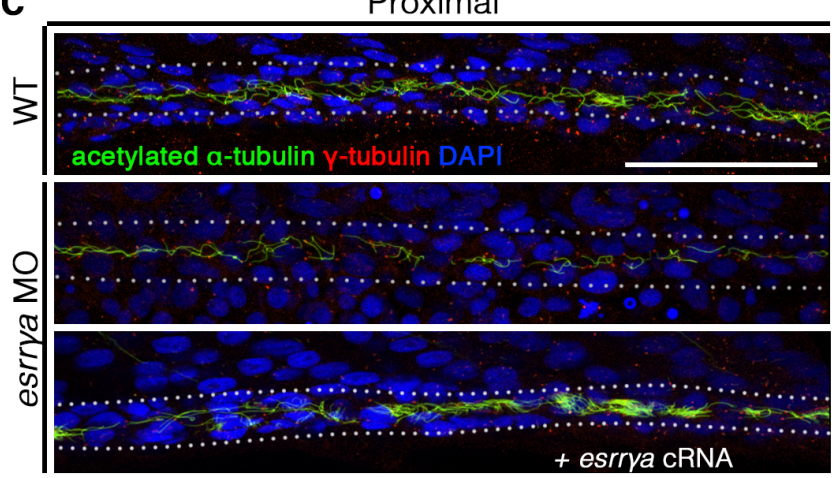

D

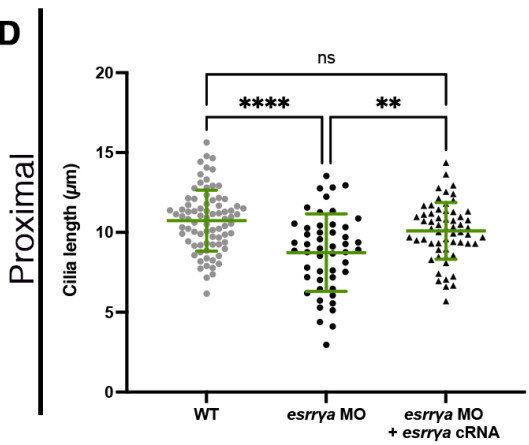

G
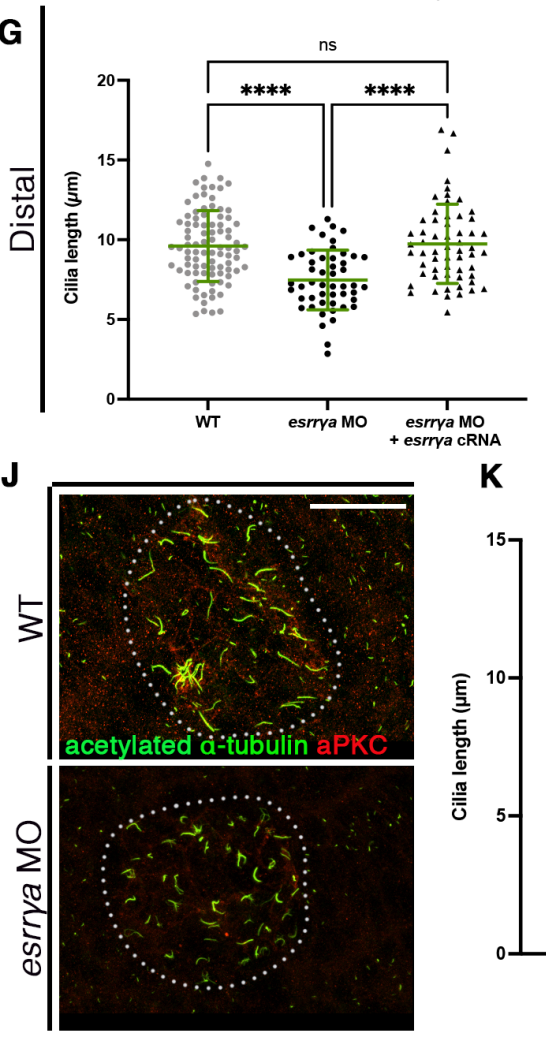

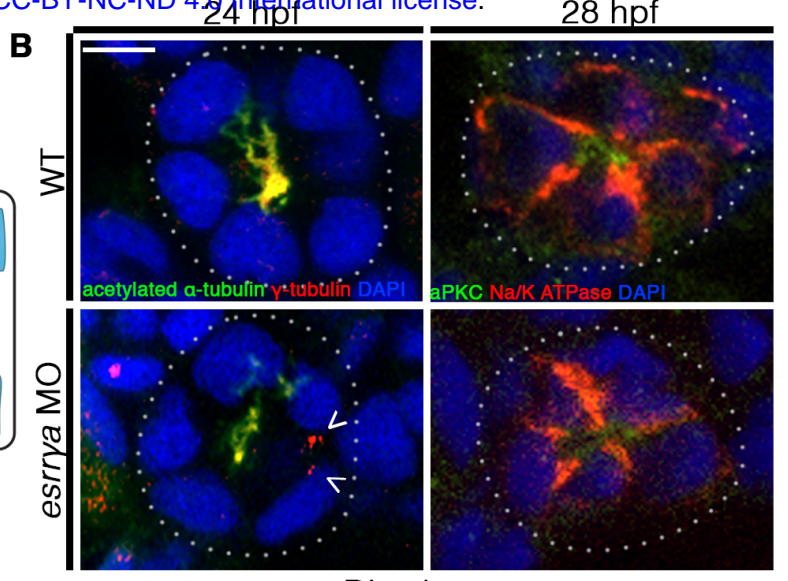

Distal
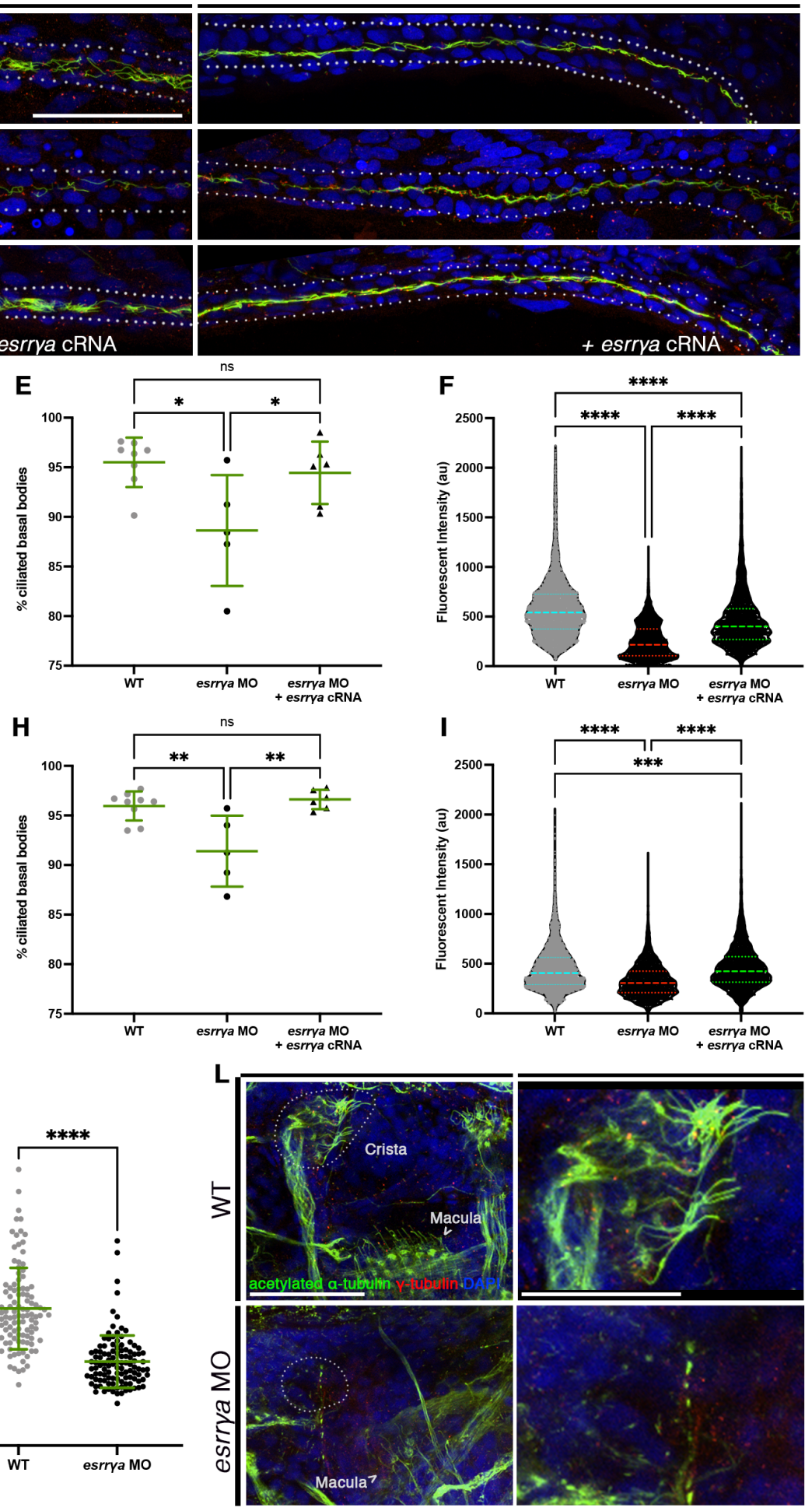
bioRxiv preprint doi: https://doi.org/10.1101/2021.11.17.468871; this version posted November 19, 2021. The copyright holder for this preprint (which was not certified by peer review) is the author/funder, who has granted bioRxiv a license to display the preprint in perpetuity. It is made

Figure 3
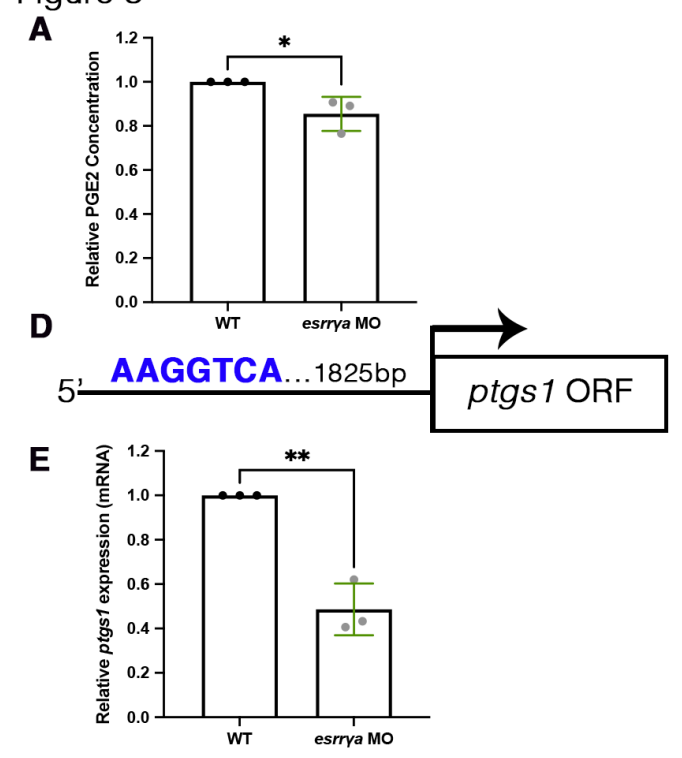
available under aCC-BY-NC-ND 4.0 International license.
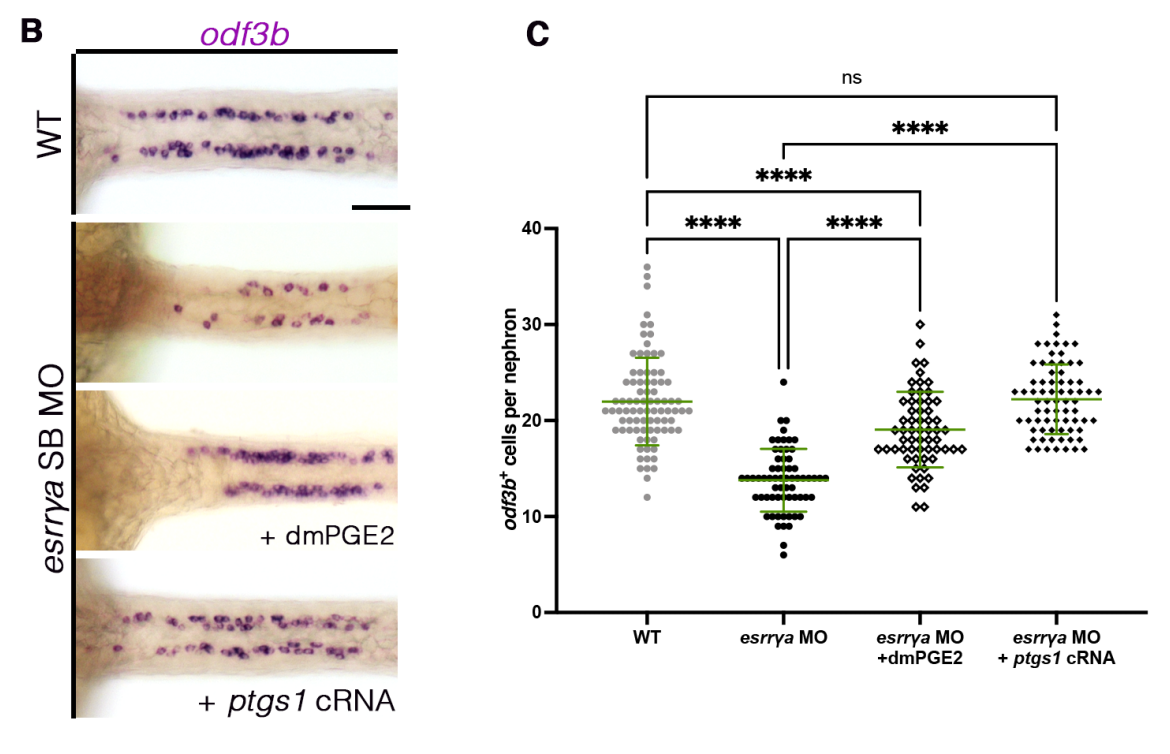

F
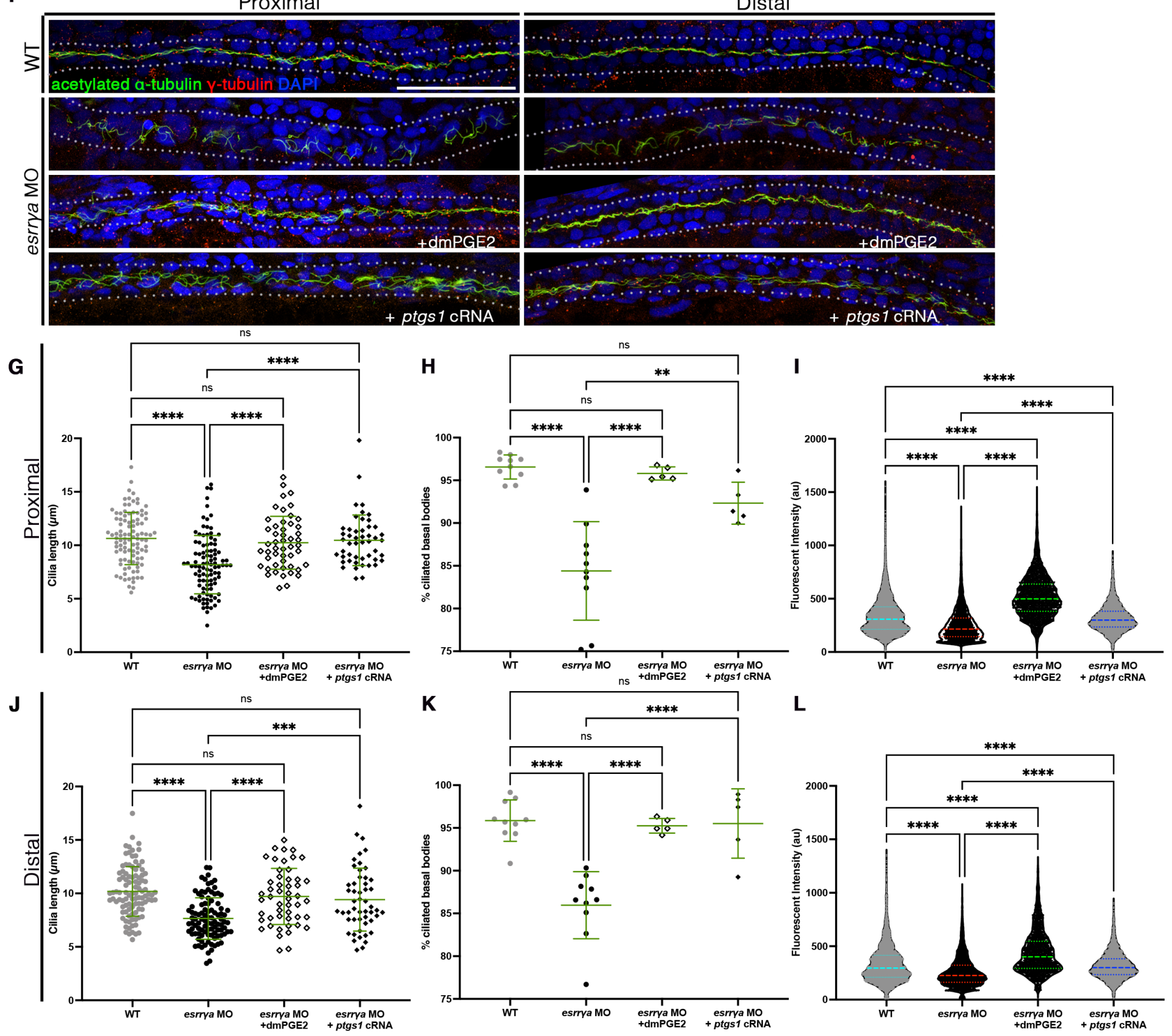
bioRxiv preprint doi: https://doi.org/10.1101/2021.11.17.468871; this version posted November 19,2021 . The copyright holder for this preprint (which was not certified by peer review) is the author/funder, who has granted bioRxiv a license to display the preprint in perpetuity. It is made

Figure 4

A
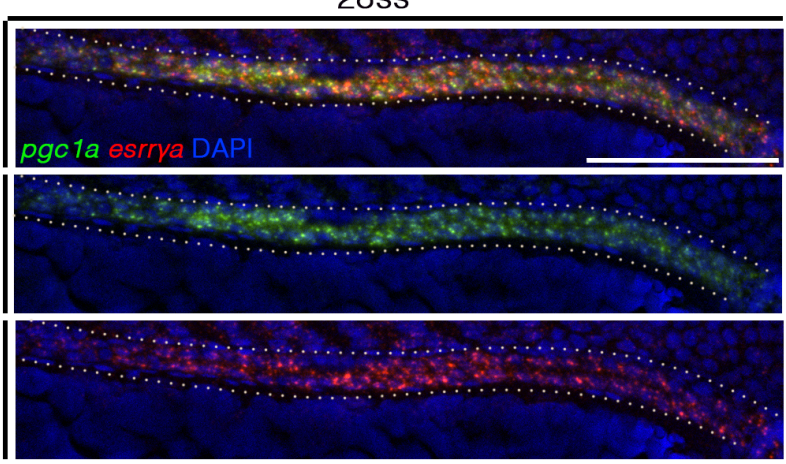

D

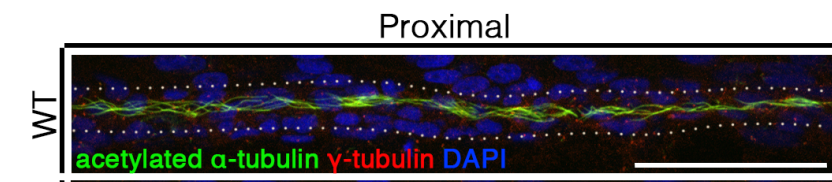

릴ำ

$\frac{\pi}{0}$
5
20
20

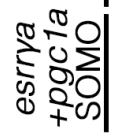

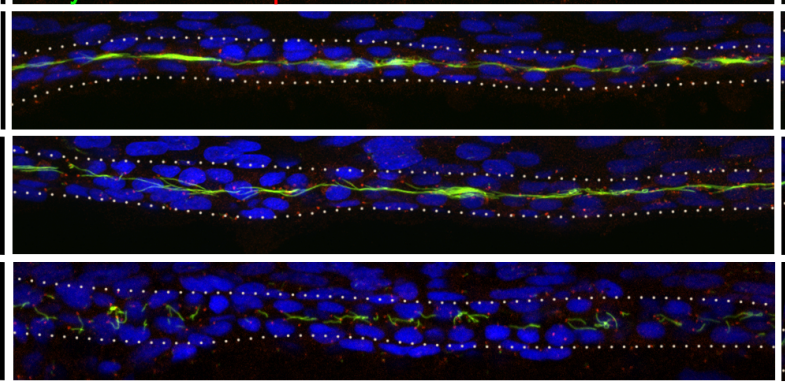

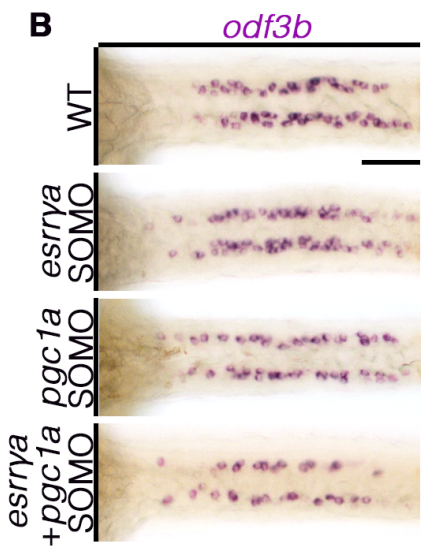

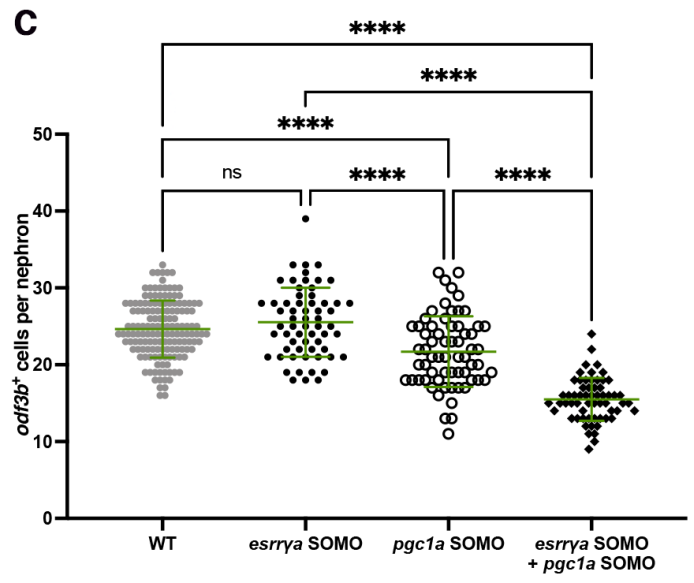

E

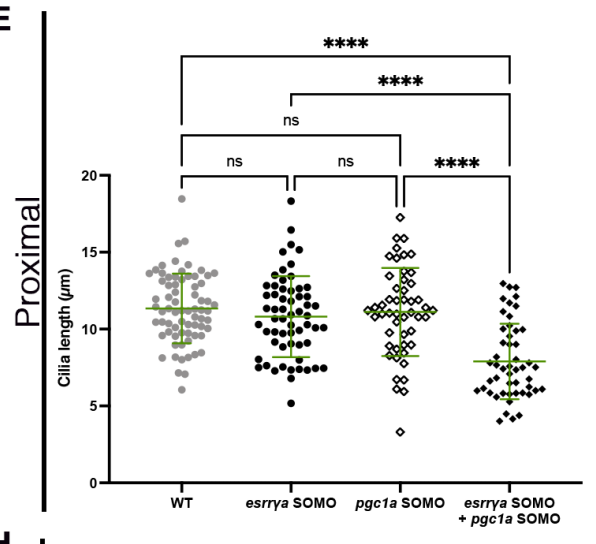

$\mathbf{H}$

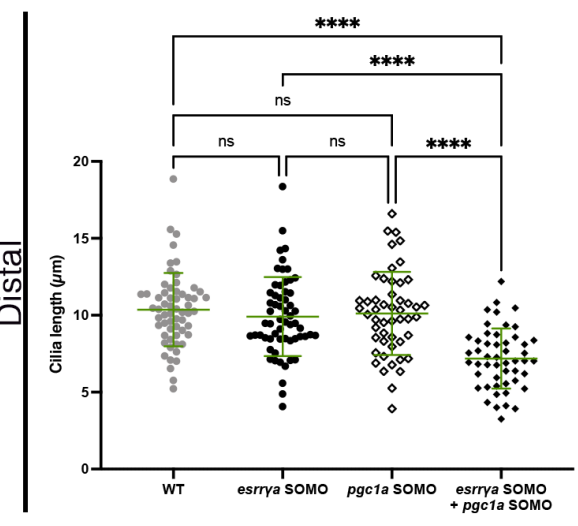

F
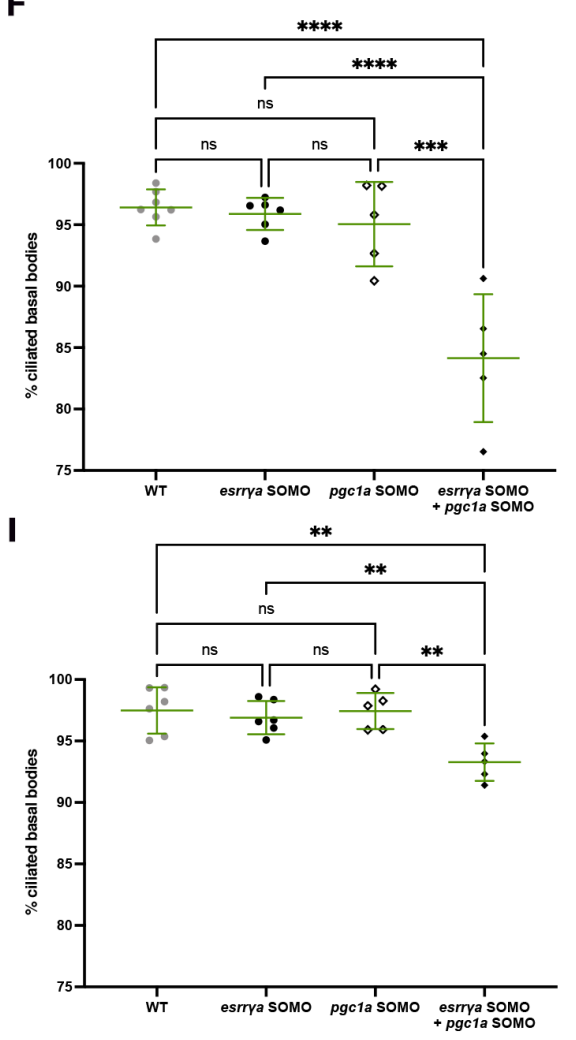

G

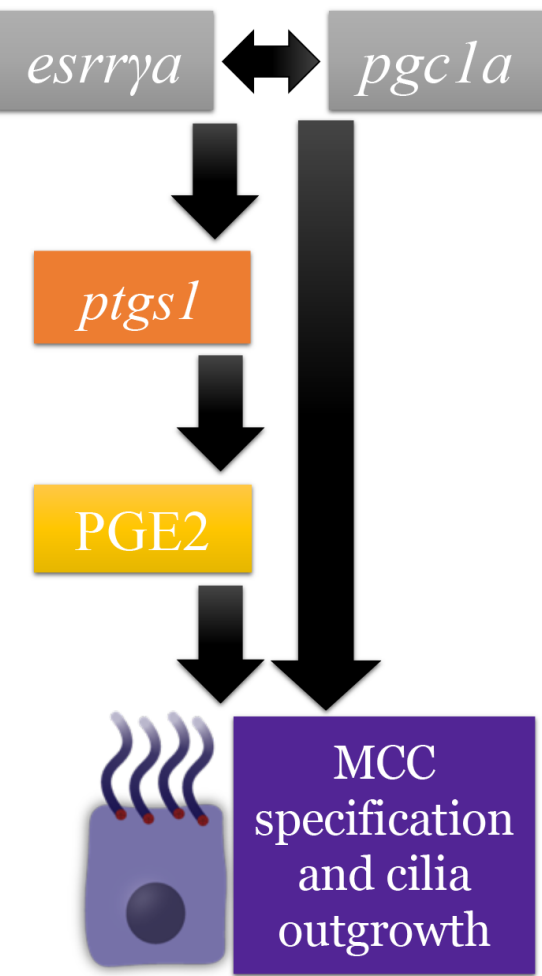


bioRxiv preprint doi: https://doi.org/10.1101/2021.11.17.468871; this version posted November 19, 2021. The copyright holder for this preprint

(which was not certified by peer review) is the author/funder, who has granted bioRxiv a license to display the preprint in perpetuity. It is made Supplement 1 available under aCC-BY-NC-ND 4.0 International license.
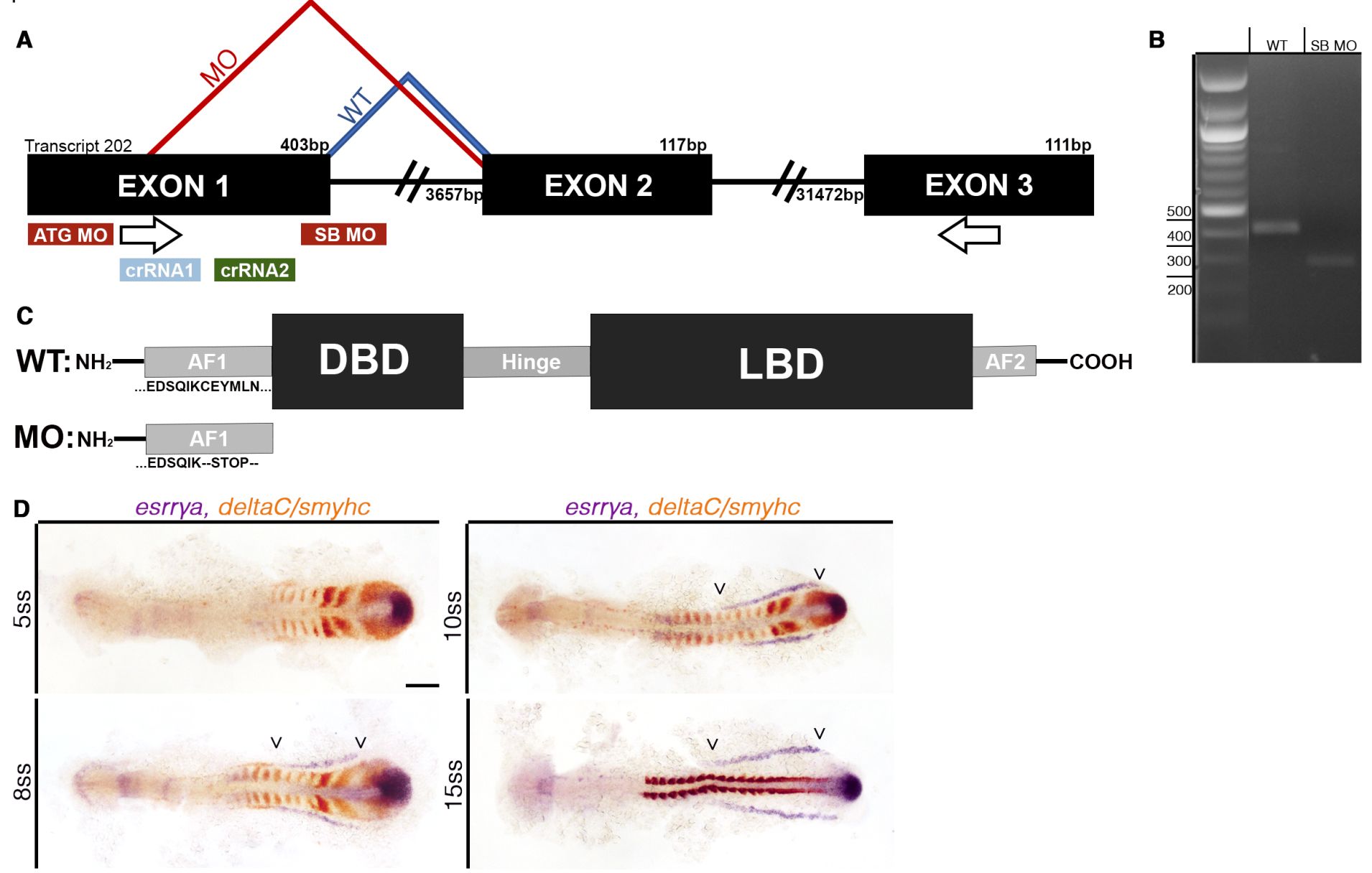

E

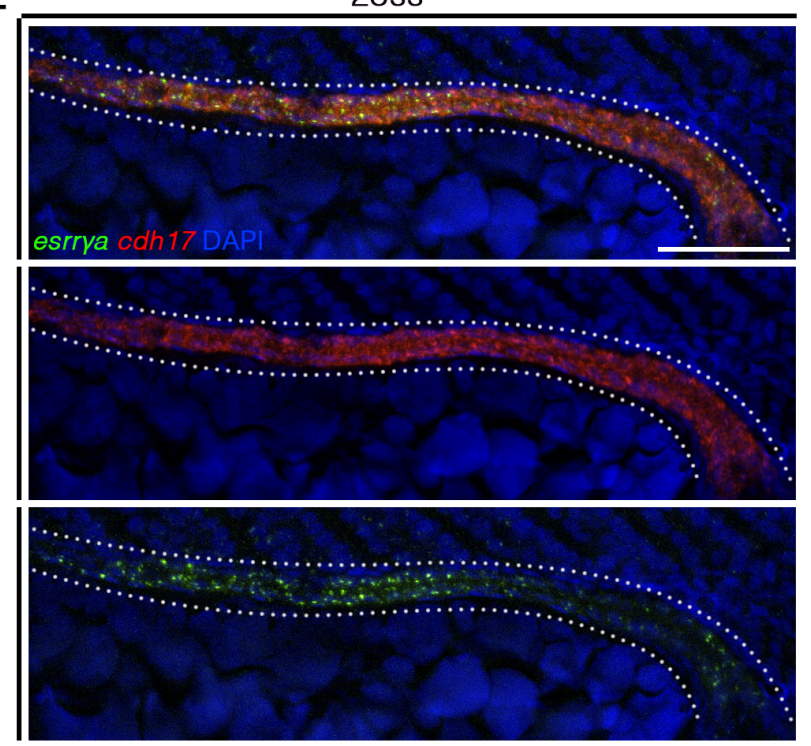

G

odf $3 b$

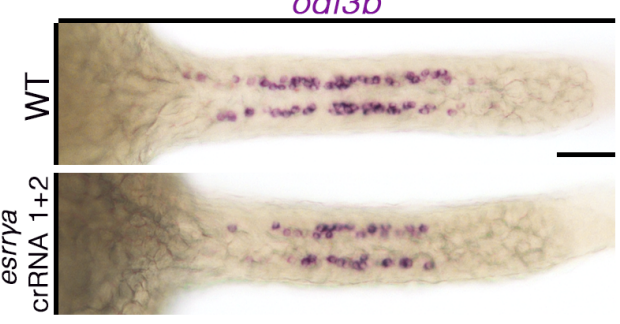

$\mathbf{F}$

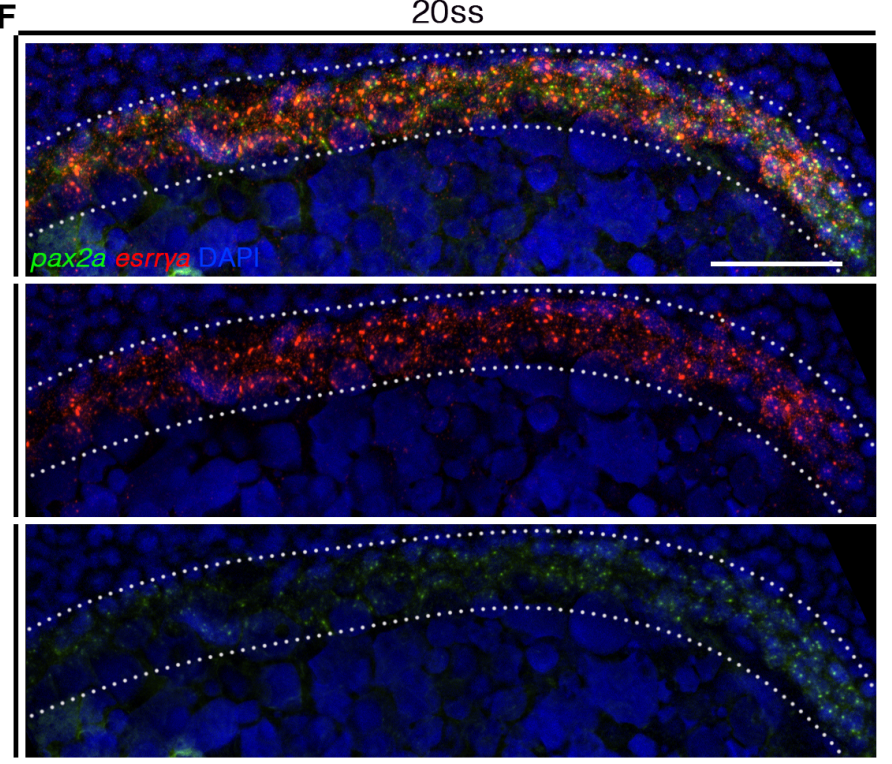


bioRxiv preprint doi: https://doi.org/10.1101/2021.11.17.468871; this version posted November 19, 2021. The copyright holder for this preprint

(which was not certified by peer review) is the author/funder, who has granted bioRxiv a license to display the preprint in perpetuity. It is made Supplement 2 available under aCC-BY-NC-ND 4.0 International license.
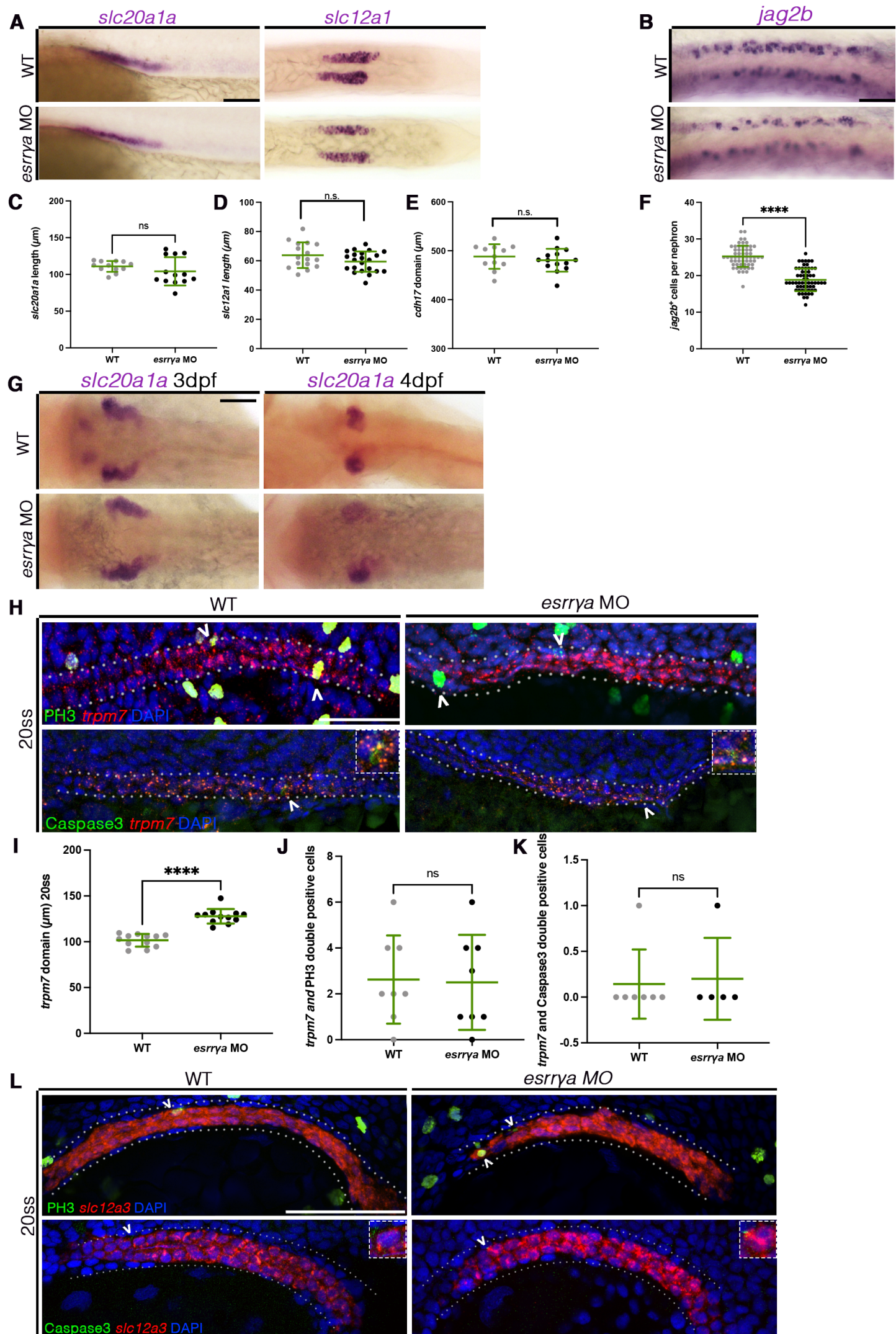

esrrya MO
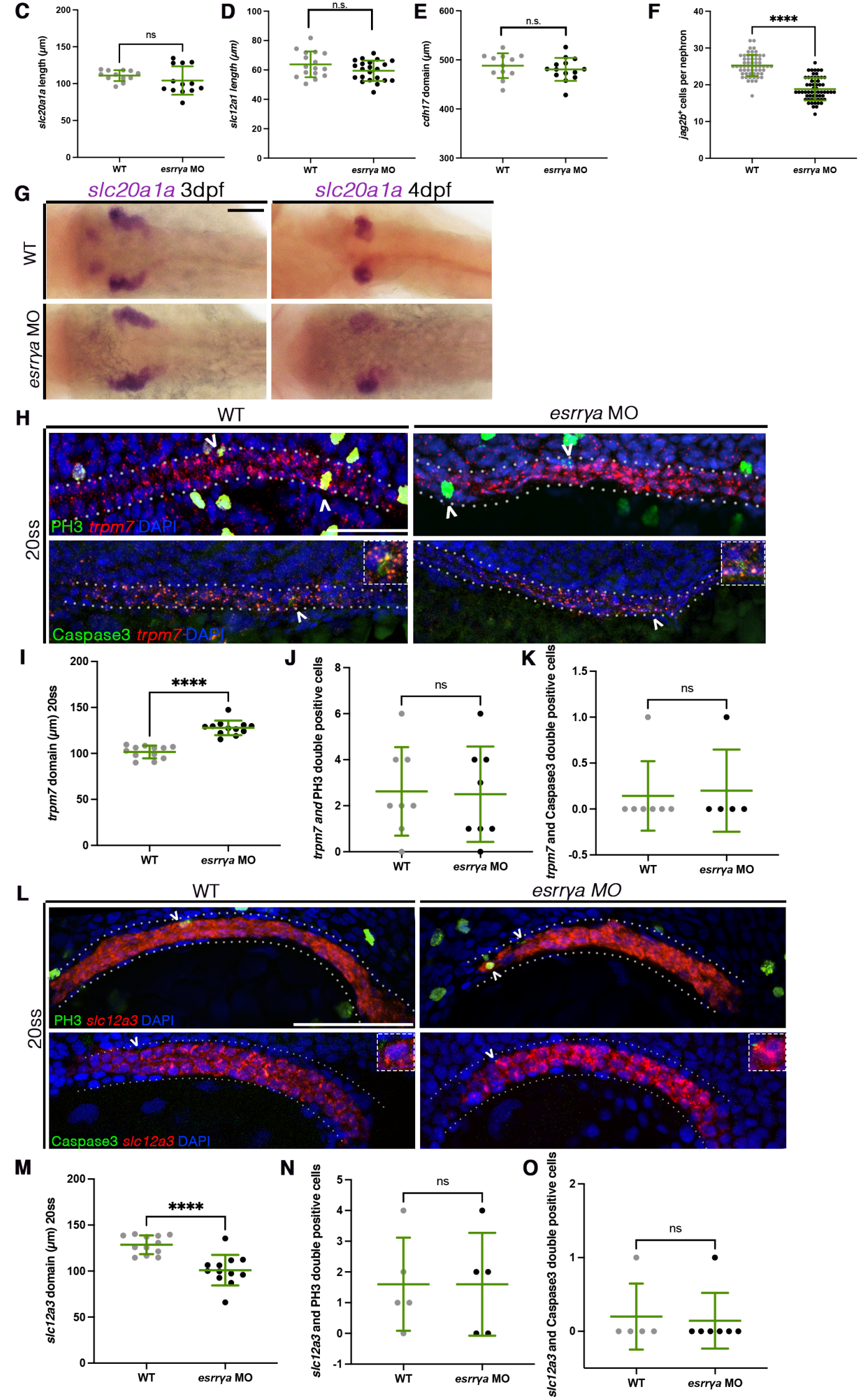
bioRxiv preprint doi: https://doi.org/10.1101/2021.11.17.468871; this version posted November 19,2021 . The copyright holder for this preprint (which was not certified by peer review) is the author/funder, who has granted bioRxiv a license to display the preprint in perpetuity. It is made Supplement 3 available under aCC-BY-NC-ND 4.0 International license.

A
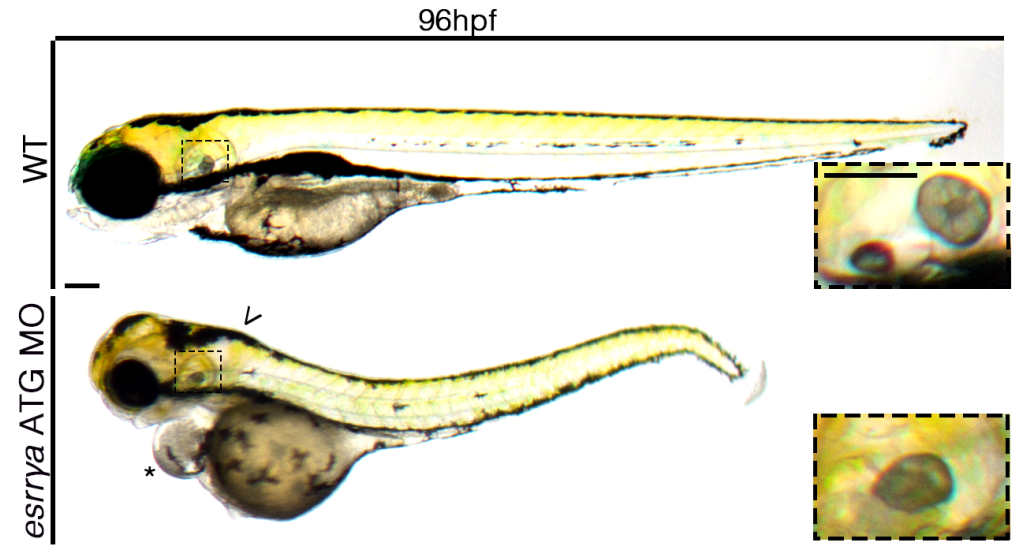

D

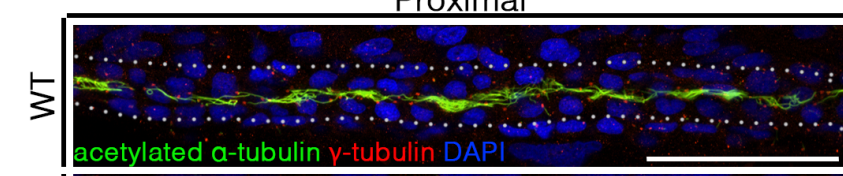

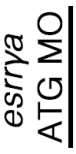

E

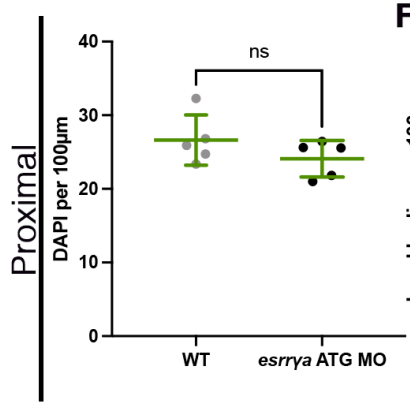

$\mathbf{J}$
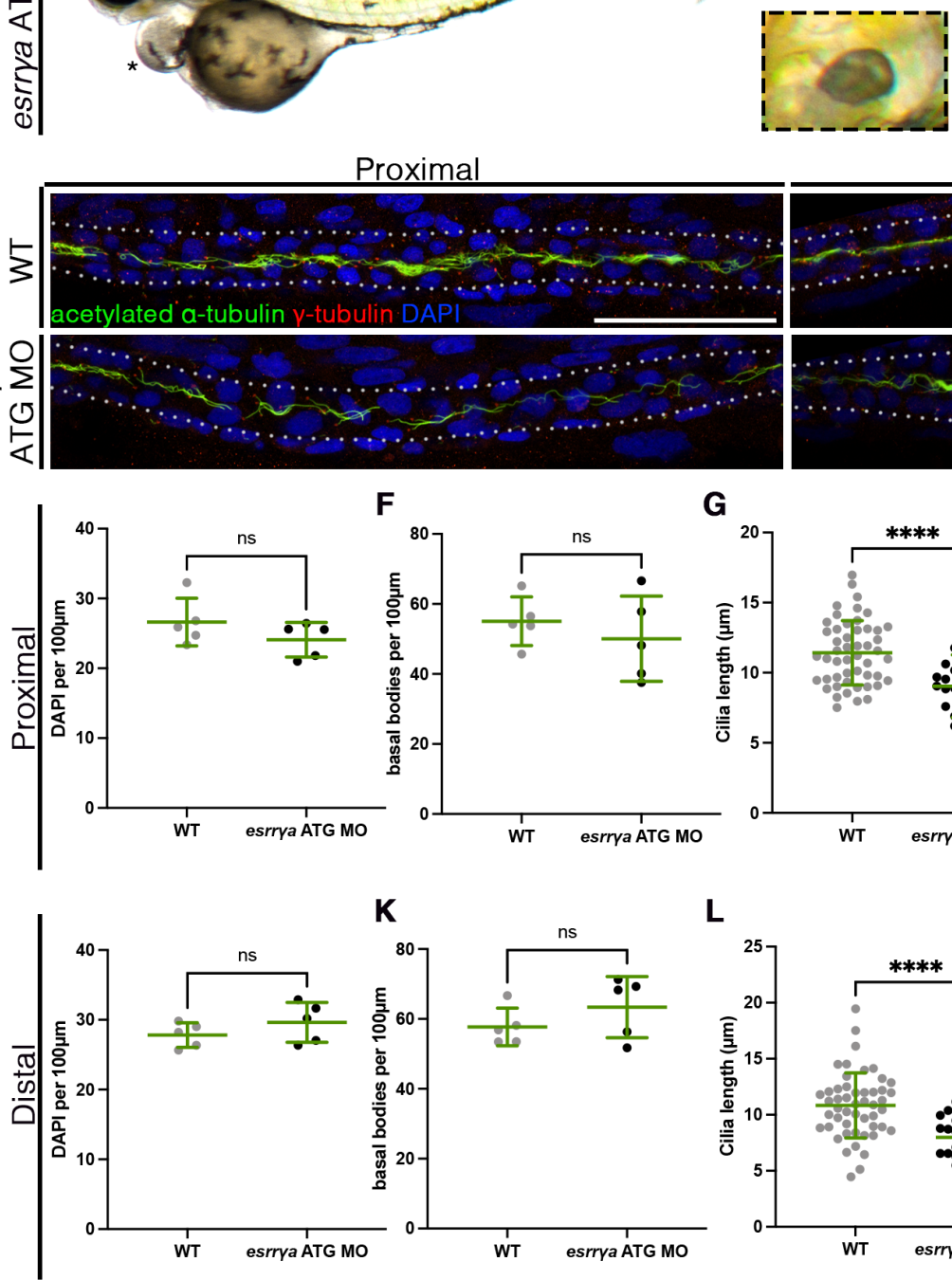

$\mathbf{F}$

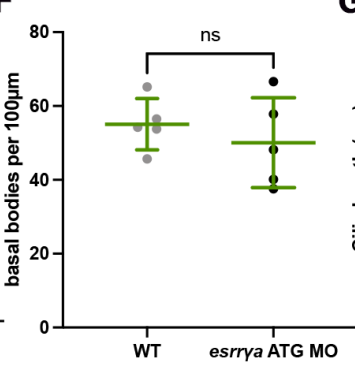

$\mathbf{L}$
$\mathbf{B}$

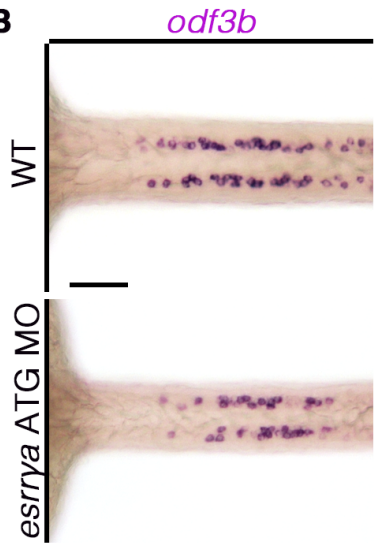

C

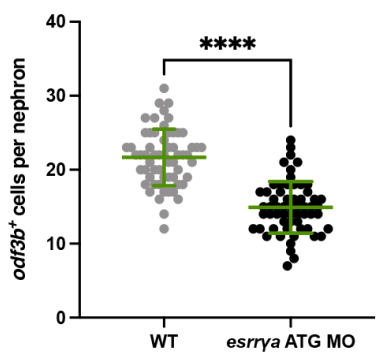

Distal

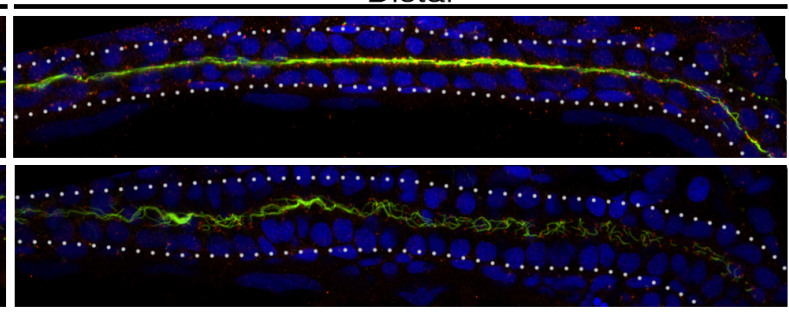

G

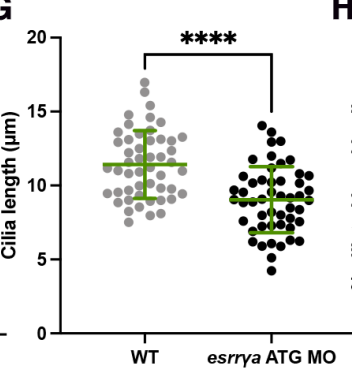

H

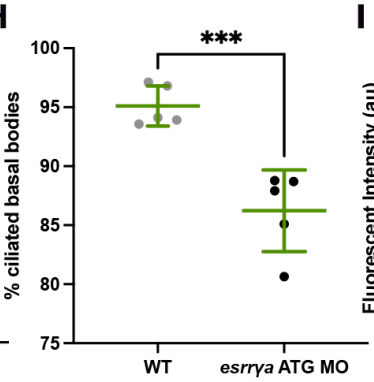

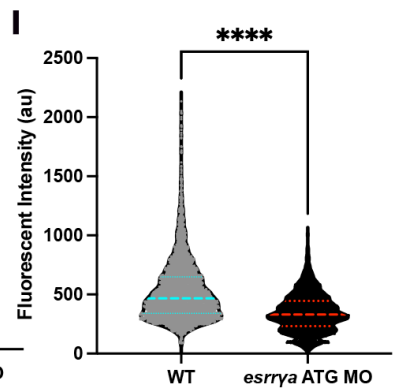

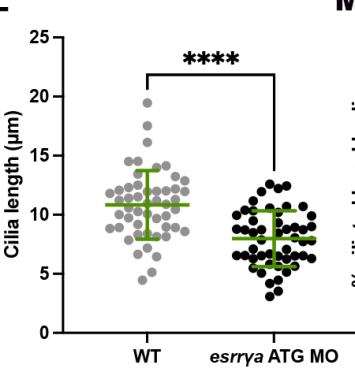

N

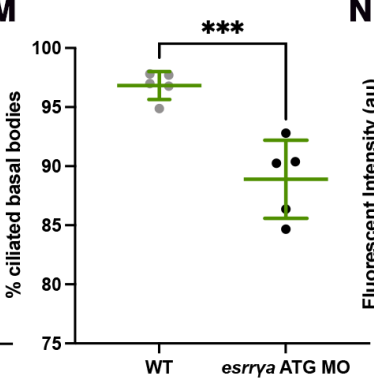

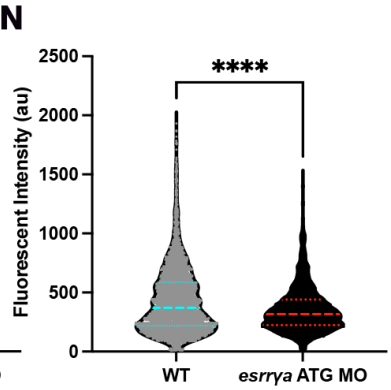


bioRxiv preprint doi: https://doi.org/10.1101/2021.11.17.468871; this version posted November 19,2021 . The copyright holder for this preprint (which was not certified by peer review) is the author/funder, who has granted bioRxiv a license to display the preprint in perpetuity. It is made Supplement 4
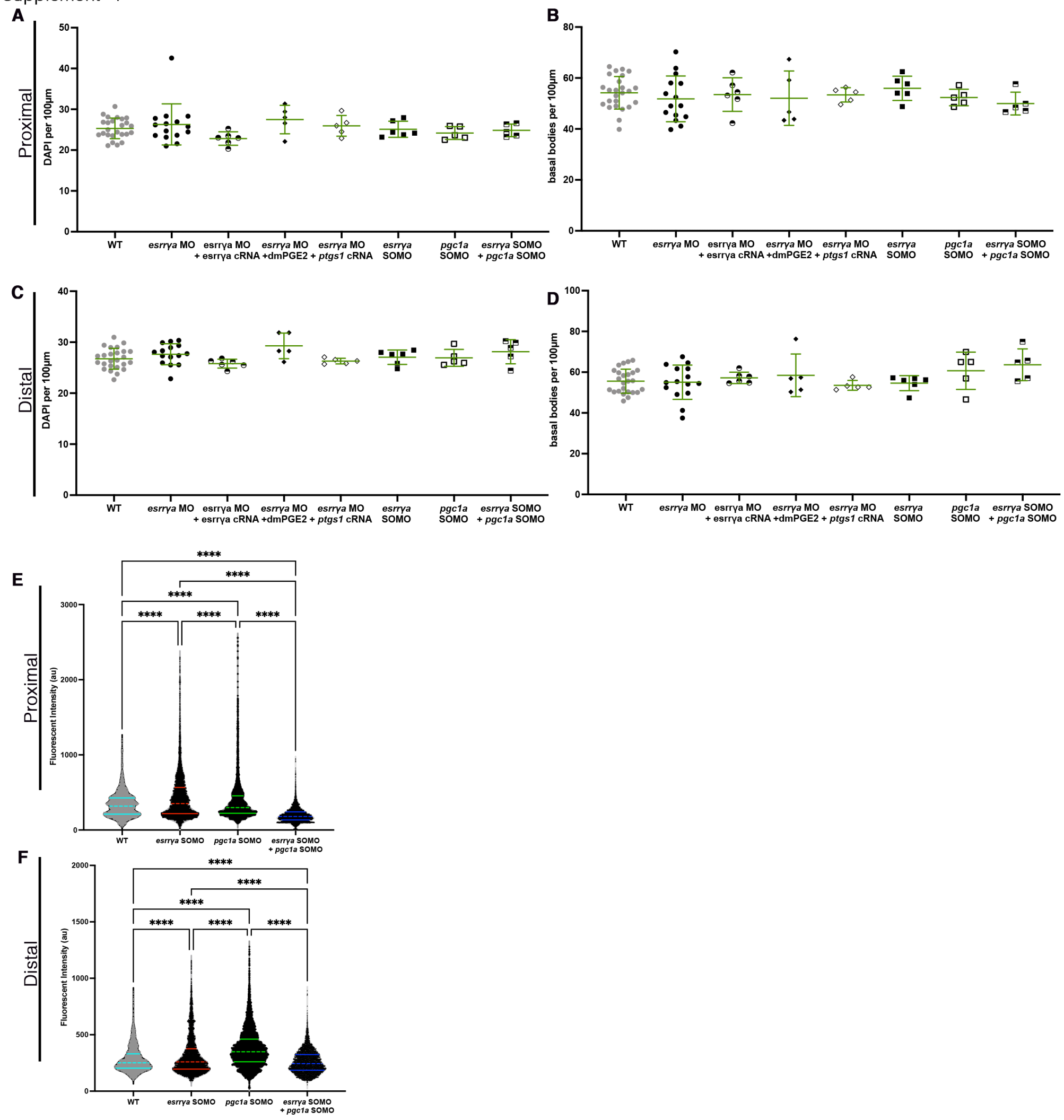
bioRxiv preprint doi: https://doi.org/10.1101/2021.11.17.468871; this version posted November 19, 2021. The copyright holder for this preprint (which was not certified by peer review) is the author/funder, who has granted bioRxiv a license to display the preprint in perpetuity. It is made Supplement 5 available under aCC-BY-NC-ND 4.0 International license.
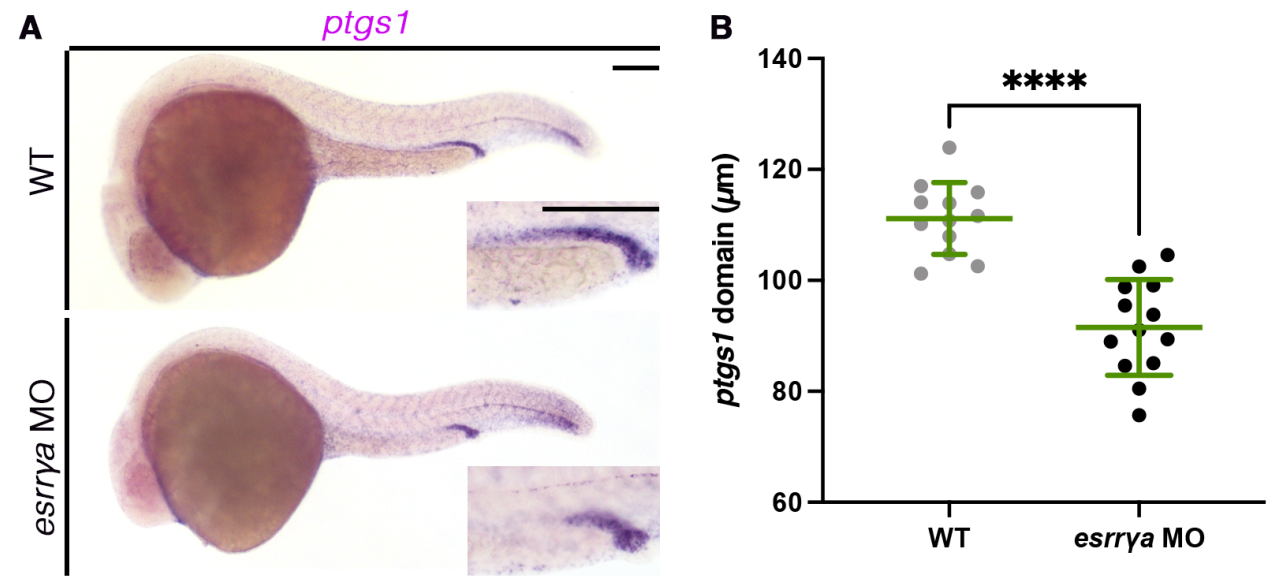